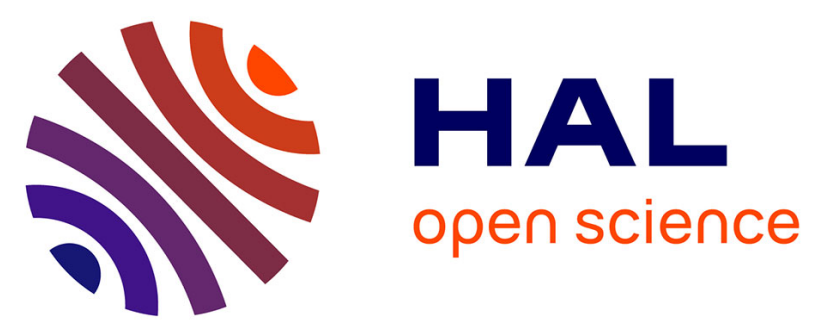

\title{
Product Detection of the CH Radical Reactions with Ammonia and Methyl-Substituted Amines
}

\author{
Jérémy Bourgalais, Kacee L. Caster, Olivier Durif, David L. Osborn, \\ Sébastien D. Le Picard, Fabien Goulay
}

\section{- To cite this version:}

Jérémy Bourgalais, Kacee L. Caster, Olivier Durif, David L. Osborn, Sébastien D. Le Picard, et al.. Product Detection of the $\mathrm{CH}$ Radical Reactions with Ammonia and Methyl-Substituted Amines. Journal of Physical Chemistry A, 2019, 123 (11), pp.2178-2193. 10.1021/acs.jpca.8b11688 . hal02089225

HAL Id: hal-02089225

https://hal-univ-rennes1.archives-ouvertes.fr/hal-02089225

Submitted on 11 Apr 2019

HAL is a multi-disciplinary open access archive for the deposit and dissemination of scientific research documents, whether they are published or not. The documents may come from teaching and research institutions in France or abroad, or from public or private research centers.
L'archive ouverte pluridisciplinaire HAL, est destinée au dépôt et à la diffusion de documents scientifiques de niveau recherche, publiés ou non, émanant des établissements d'enseignement et de recherche français ou étrangers, des laboratoires publics ou privés. 


\section{Product Detection of the CH Radical Reactions with Ammonia and Methyl-Substituted Amines}

Jeremy Bourgalais, ${ }^{1}$ Kacee L. Caster, ${ }^{2}$ Olivier Durif, ${ }^{3}$ David L. Osborn, ${ }^{4}$ Sebastien D. Le Picard, ${ }^{3}$ and Fabien Goulay ${ }^{2, *}$

${ }^{1}$ LATMOS/IPSL, UVSQ Université Paris-Saclay, Sorbonne Université, CNRS, Guyancourt, France

${ }^{2}$ Department of Chemistry, West Virginia University, Morgantown, West Virginia 26506, USA ${ }^{3}$ Astrophysique de Laboratoire, Univ Rennes, CNRS, IPR (Institut de Physique de Rennes) UMR 6251, F-35000 Rennes, France

${ }^{4}$ Combustion Research Facility, Mail Stop 9055, Sandia National Laboratories, Livermore, California 94551, USA

*Corresponding Author: Fabien.Goulay@mail.wvu.edu 


\begin{abstract}
Reactions of the methylidyne $(\mathrm{CH})$ radical with ammonia $\left(\mathrm{NH}_{3}\right)$, methylamine $\left(\mathrm{CH}_{3} \mathrm{NH}_{2}\right)$, dimethylamine $\left(\left(\mathrm{CH}_{3}\right)_{2} \mathrm{NH}\right)$, and trimethylamine $\left(\left(\mathrm{CH}_{3}\right)_{3} \mathrm{~N}\right)$, have been investigated under multiple collision conditions at $373 \mathrm{~K}$ and 4 Torr. The reaction products are detected using soft photoionization coupled to orthogonal acceleration time-of-flight mass spectrometry at the Advanced Light Source (ALS) synchrotron. Kinetic traces are employed to discriminate between $\mathrm{CH}$ reaction products and products from secondary or slower reactions. Branching ratios for isomers produced at a given mass and formed by a single reaction are obtained by fitting the observed photoionization spectra to linear combinations of pure compound spectra. The reaction of the $\mathrm{CH}$ radical with ammonia is found to form mainly imine, $\mathrm{HN}=\mathrm{CH}_{2}$, in line with an addition-elimination mechanism. The singly methyl substituted imine is detected for the $\mathrm{CH}$ reactions with methylamine, dimethylamine, and trimethylamine. Dimethylimine isomers are formed by the reaction of $\mathrm{CH}$ with dimethylamine, while trimethylimine is formed by the $\mathrm{CH}$ reaction with trimethylamine. Overall, the temporal profiles of the products are not consistent with the formation of amino carbene products in the reaction flow tube. In the case of the reactions with methylamine and dimethylamine, product formation is assigned to an addition-elimination mechanism similar to that proposed for the $\mathrm{CH}$ reaction with ammonia. However, this mechanism cannot explain the products detected by the reaction with trimethylamine. A C-H insertion pathway may become more probable as the number of methyl group increases.
\end{abstract}




\section{INTRODUCTION}

Ammonia and its amine derivatives are emitted as gases in the atmosphere from a variety of sources such as biomass burning, vegetation, combustion, as well as industry. ${ }^{1,2}$ These nitrogen-containing molecules are of special interest in combustion environments where they impact the oxidation and ignition of hydrocarbon fuels. ${ }^{3,4}$ In addition, their chemistry in reactive carbon-rich environments may play a significant role in the formation of $\mathrm{NO}_{\mathrm{x}} \cdot{ }^{5-10} \mathrm{An}$ improved utilization of biomass-derived nitrogen-containing compounds as fuels and a better understanding of the role of amines in combustion both require a systematic study of the chemistry of ammonia and substituted amines with combustion relevant radicals.

A large number of experiments have been performed to investigate the reaction of ammonia with radicals such as $\mathrm{OH}, \mathrm{CN}, \mathrm{C}_{2} \mathrm{H}$, and $\mathrm{CH} .{ }^{11-15}$ Although its reaction with the $\mathrm{OH}$ radical is found to be slow $\left(<5 \times 10^{-13} \mathrm{~cm}^{3} \mathrm{~s}^{-1}\right.$ from $230 \mathrm{~K}$ to $\left.450 \mathrm{~K}\right),{ }^{11}$ ammonia reacts at a significant fraction of the collision rate with the $\mathrm{CN},{ }^{12} \mathrm{C}_{2} \mathrm{H},{ }^{13}$ and $\mathrm{CH}$ radicals. ${ }^{14}$ In the case of the reactions with $\mathrm{OH}$ and $\mathrm{CN}$, the products are predicted to mostly be $\mathrm{NH}_{2}+\mathrm{H}_{2} \mathrm{O}$ and $\mathrm{NH}_{2}+$ HCN. ${ }^{13,16,17}$ The reaction with $\mathrm{OH}$ proceeds directly through a $\mathrm{HO}-\mathrm{HNH}_{2}$ abstraction saddle point, ${ }^{16}$ while the reaction with $\mathrm{CN}$ initially forms a $\mathrm{NC}-\mathrm{NH}_{3}$ adduct that may rearrange and dissociate to form the final products. ${ }^{13,17}$ The most exhaustive experimental and theoretical studies have been performed for the $\mathrm{CH}+\mathrm{NH}_{3}$ reaction. ${ }^{15}$ The mechanism has been assigned as addition-elimination, as further described in this introduction. Kinetic investigations with methyl-substituted amines are scarcer and data are available only for reactions with $\mathrm{OH}$ and $\mathrm{CH}$ radicals. ${ }^{14,18-22}$ Reactions with the $\mathrm{OH}$ radical proceed with a rate coefficient on the order of $1 \times 10^{-11} \mathrm{~cm}^{3} \mathrm{~s}^{-1}$ and are predicted to occur through interaction of the $\mathrm{OH}$ radical with an $\mathrm{H}$ atom of both the amine and methyl groups to give the abstraction products. ${ }^{18}$ Reactions of the $\mathrm{CH}$ radical with methyl substituted amines are fast $\left(>1 \times 10^{-10} \mathrm{~cm}^{3} \mathrm{~s}^{-1}\right)^{14}$ although no mechanistic information is available. 
The methylidyne $(\mathrm{CH})$ radical is an important reactive intermediate detected in hydrocarbon flames (e.g., methane, acetylene, ethene, ethane, propene, propane). ${ }^{13,16,23,24}$ Its barrier-less addition toward a large number of organic and inorganic functional groups is due to the carbon atom having both one singly occupied and one empty non-bonding molecular orbital. Its formation in flames, along with other fuel-derived $\mathrm{C}_{1}$-radicals (e.g., $\mathrm{CH}_{3}, \mathrm{CH}_{2}$ and C), occurs primarily from oxidation of small hydrocarbon compounds (e.g., methane, acetylene). ${ }^{17,25}$ Once formed, the $\mathrm{CH}$ radical is likely to play a role in the formation of soot precursors through generation of small cyclic hydrocarbons. ${ }^{23-28}$ A major interest of the $\mathrm{CH}$ radical in combustion is its ability to react with molecular nitrogen to form NCN, which is the dominant source of prompt NO formation in turbulent diffusion flames. ${ }^{17,25-38}$ Its reaction with ammonia is also included in a recent combustion model. ${ }^{25}$ As fuel complexity is increased, there is a need for additional data about the reaction of the $\mathrm{CH}$ radical with nitrogen containing hydrocarbons.

Zabarnick et al. ${ }^{14}$ performed the first kinetic measurements of $\mathrm{CH}$ radical reactions with ammonia and methyl substituted amines. They employed pulsed laser photolysis (PLP) and laser-induced fluorescence (LIF) to measure rate constants for $\mathrm{CH}$ with $\mathrm{NH}_{3}, \mathrm{CH}_{3} \mathrm{NH}_{2}$, $\left(\mathrm{CH}_{3}\right)_{2} \mathrm{NH}$ and $\left(\mathrm{CH}_{3}\right)_{3} \mathrm{~N}$ at temperatures ranging from room temperature up to $677 \mathrm{~K}$. Based on the observed large rate coefficients they suggested an insertion-elimination mechanism of $\mathrm{CH}$ into one of the $\mathrm{N}-\mathrm{H}$ bonds followed by rapid dissociation of the energized complex. Bocherel et al. ${ }^{39}$ measured the $\mathrm{CH}+\mathrm{NH}_{3}$ reaction also using a PLP-LIF technique in a supersonic flow reactor between 23 and $295 \mathrm{~K}$. The reaction rate coefficient is $1.37 \times 10^{-10} \mathrm{~cm}^{3} \mathrm{~s}^{-1}$ at $295 \mathrm{~K}$ and displays no significant temperature $\left(2.21 \times 10^{-10} \mathrm{~cm}^{3} \mathrm{~s}^{-1}\right.$ at $\left.23 \mathrm{~K}\right)$ or pressure dependences in agreement with the study of Zabarnick et al. ${ }^{14}$ More recently Blitz et al. ${ }^{15}$ investigated the products of the $\mathrm{CH}+\mathrm{NH}_{3}$ reaction by measuring the $\mathrm{H}$-atom branching ratio using LIF. The close to unity $\mathrm{H}$-atom branching ratio combined with high-level (MCSCF/CASSCF) 
calculations ${ }^{15}$ support an insertion-elimination mechanism similar to that proposed for the reactions of $\mathrm{CH}$ with saturated hydrocarbons. ${ }^{40}$ In the case of ammonia the insertion is found to proceed first through the formation of a dative bond ${ }^{15}$ between the carbon and the nitrogen atoms. ${ }^{15}$

The aim of the present study is to obtain a general mechanism for the reaction of $\mathrm{CH}$ with amines. For this purpose we present a systematic investigation of the products formed by reactions of ground state methylidyne $\mathrm{CH}\left(\mathrm{X}^{2} \Pi\right)$ radicals with $\mathrm{NH}_{3}$ and three methyl derivatives: methylamine (MA) $\mathrm{CH}_{3} \mathrm{NH}_{2}$, dimethylamine (DA) $\left(\mathrm{CH}_{3}\right)_{2} \mathrm{NH}$, and trimethylamine (TA) $\left(\mathrm{CH}_{3}\right)_{3} \mathrm{~N}$. To probe the reaction products, experiments are performed in a flow reactor under thermal conditions (373 K and 4 Torr) at the Advanced Light Source (ALS) synchrotron of Lawrence Berkeley National Laboratory (LBNL). Products sampled from the flow are detected using tunable vacuum ultraviolet (VUV) photoionization and time-of-flight mass spectrometry. Kinetic traces and photoionization spectra supported by thermodynamic and Franck-Condon factor calculations of the species have been used to infer the primary products of the reactions.

\section{EXPERIMETAL PROCEDURE}

The experiments are performed in a slow flow reactor coupled to a tunable VUV photoionization orthogonal acceleration time-of-flight mass spectrometer. A detailed description of the apparatus has been given in the literature ${ }^{41-43}$ and only a brief description is given here. The reactions take place in a flow tube at $373 \mathrm{~K}$ and at a pressure of 4 Torr (total density $\sim 10^{17} \mathrm{~cm}^{-3}$ ). The $100 \mathrm{sccm}$ gas flow consists of a large excess of He with $10 \%$ nitrogen and small amounts of $\mathrm{CH}$-radical precursor (bromoform) and reagent gases (ammonia, MA, DMA, or TMA) with typical densities of $\sim 10^{13} \mathrm{~cm}^{-3}$ and $\sim 10^{14} \mathrm{~cm}^{-3}$ respectively. The bromoform $\left(\mathrm{CHBr}_{3}\right)$ is placed in a glass vessel and its vapor carried into the main carrier gas flow by bubbling a controlled flow of He through the liquid. The purities of gases are: 
bromoform (99\%), $\mathrm{CDBr}_{3}\left(\geq 99 \%, \geq 99.5\right.$ atom \% D), $\mathrm{NH}_{3}(\geq 99.9 \%), \mathrm{CH}_{3} \mathrm{NH}_{2}(\geq 99 \%)$, $\left(\mathrm{CH}_{3}\right)_{2} \mathrm{NH}(\geq 99 \%),\left(\mathrm{CH}_{3}\right)_{3} \mathrm{~N}(\geq 99 \%)$.

$\mathrm{CH}$ radicals are generated by excimer laser photolysis at $248 \mathrm{~nm}$ with a $4 \mathrm{~Hz}$ repetition rate. The laser power output is typically $266 \mathrm{~mJ}$ per pulse for a $20 \mathrm{~ns}$ pulse duration, with a photolysis fluence inside the flow tube of $\sim 20-50 \mathrm{~mJ} \mathrm{~cm}{ }^{-2}$. Photodissociation occurs via successive absorption of photons eliminating multiple halogen atoms leading to $\mathrm{CH}$ number density of about $2.5 \times 10^{10} \mathrm{~cm}^{-3}$ in the reaction flow. ${ }^{44,45}$

The gas mixture is sampled through a pinhole halfway down the flow tube into a highvacuum chamber. A skimmer generates a molecular beam into the ionization chamber where species are ionized by the quasi-continuous tunable VUV synchrotron radiation of the ALS. The formed ions are detected through time-of-flight mass spectrometry by recording their arrival time with respect to the extraction pulse and laser pulse. The setup leads to complete time- and energy-resolved mass spectra by averaging 200-500 laser pulses for each ionizing photon energy. The photoionization spectra are obtained from three independent data sets, averaged and integrated, over the mass-to-charge ratio and time window of interest. In the following sections a time window up to $80 \mathrm{~ms}$ was interrogated after the laser pulse. Mass spectra, kinetic time traces, and photoionization spectra are corrected for pre-photolysis signals by subtracting the average ion counts in a $20 \mathrm{~ms}$ time window before the laser pulse. Having subtracted this time-independent signal, the data in the figures represents the change of signals as a result of the reactive species created by the laser pulse. Positive signals represent species created because of the laser pulse, whereas negative signals correspond to species that are depleted following irradiation. Finally, all signals are normalized to variations in VUV photon flux that is monitored using a calibrated photodiode. 


\section{COMPUTATIONAL METHODS}

Electronic structure calculations of neutral species and their cations leading to their optimized geometries have been performed using the Gaussian09 package with the B3LYP/CBSB7 method. Details about the calculations have been discussed elsewhere. ${ }^{41,42,46,47}$ Heats of reaction, and adiabatic and vertical ionization energies, are calculated using the CBS-QB3 composite method. ${ }^{48,49}$ Simulated Franck-Condon factors of isomer species are calculated at room temperature with the G09 package within the Franck-Condon approximation. ${ }^{44,50}$ Although the experiments are performed at $373 \mathrm{~K}$, the higher temperature does not result in significantly different vibrational populations. The calculated Franck-Condon factors are convolved with a Gaussian response function (FWHM of $0.025 \mathrm{eV}$ ) and integrated in order to simulate the photoionization spectra of the species assuming that direct ionization dominates the ionization process.

Saddle points for $\mathrm{H}$ - and $\mathrm{CH}_{3}$-transfer on the $\mathrm{CH}+\mathrm{CH}_{3} \mathrm{NH}_{2}$ potential energy surface (PES) are calculated using the CBS-QB3 composite method. ${ }^{48,49}$ The saddle points are verified with intrinsic reaction coordinate (IRC) calculations at the B3LYP/6-31G(d) level of theory.

\section{RESULTS}

Under the present experimental conditions (4 Torr, $373 \mathrm{~K}$, high dilution with inert gases), collisional quenching with the $\mathrm{He}(90 \%)$ and $\mathrm{N}_{2}(10 \%)$ buffer gases will rapidly thermalize all the photolysis and reaction products to the temperature of the flow. Stabilization will not compete with dissociation of the reaction intermediates as long as the unimolecular dissociation occurs with a rate higher than the collision rate $\left(<20 \times 10^{6} \mathrm{~s}^{-1}\right)$. All the initial reaction adducts formed by addition of the $\mathrm{CH}$ radicals with unsaturated hydrocarbons are expected to have lifetimes shorter or on the order of their rotational period. ${ }^{40}$ Assuming equally fast adduct isomerization and dissociation for reactions with amines under the above experimental conditions, stabilization of these intermediates through collisional quenching is not expected 
to be a significant process. For these reasons, performing the experiments under thermal conditions provides information about the unimolecular isomerization and dissociation scheme of the reaction intermediates.

The kinetic traces and photoionization spectra are recorded by irradiating a mixture of $\mathrm{CHBr}_{3}$ and the chosen amine in a $\mathrm{He} / \mathrm{N}_{2}$ mixture at $248 \mathrm{~nm}$. Along with $\mathrm{CH}\left(\mathrm{X}^{2} \Pi, v=0\right)$, bromoform photodissociation produces $\mathrm{CH}\left(\mathrm{A}^{2} \Delta\right), \mathrm{CH}\left(\mathrm{X}^{2} \Pi, v=1\right), \mathrm{Br}, \mathrm{HBr}, \mathrm{CBr}, \mathrm{CHBr}, \mathrm{Br}_{2}$ and $\mathrm{CHBr}_{2}$. The $\mathrm{CH}\left(\mathrm{A}^{2} \Delta\right)$ population decays radiatively within few microseconds after the laser pulse. ${ }^{51}$ The vibrationally excited $\mathrm{CH}\left(\mathrm{X}^{2} \Pi, v=1\right)$ radicals are efficiently quenched by adding nitrogen to the main flow. ${ }^{28,52}$ The three body reaction of the $\mathrm{CH}\left(\mathrm{X}^{2} \Pi, \mathrm{v}=0\right)$ radical with molecular nitrogen is slow ${ }^{53}$ at the pressure of the flow and is unlikely to affect the observed product distributions. Reactions of $\mathrm{CBr}$ with small unsaturated hydrocarbons are several orders of magnitude slower at the present temperature $46,47,50,54-56$ than those for reactions of the $\mathrm{CH}$ radical. ${ }^{54,55,57,58}$ Similarly slow kinetics between $\mathrm{CBr}$ and amines would allow discriminating between $\mathrm{CBr}$ and $\mathrm{CH}$ reaction products. At $248 \mathrm{~nm}$ the singlet $\mathrm{CHBr}$ carbene is expected to be formed in very low concentrations compared to the $\mathrm{CH}$ radical. ${ }^{59}$ Its reaction with ammonia or the methyl-substituted amine reactants may form products through $\mathrm{HBr}-\mathrm{loss}$ at the same $\mathrm{m} / \mathrm{z}$ as the $\mathrm{CH}$ reaction products. There are no kinetic data available for the reactions of halocarbenes with amines. In the case of reactions with DMA and TMA, signals are observed at $\mathrm{m} / \mathrm{z}$ values corresponding to dimethyl and trimethyl substituted amines plus $\mathrm{C}^{79} \mathrm{Br} / \mathrm{C}^{81} \mathrm{Br}$ isotopes. This indicates that the methyl substituted amines reacts with $\mathrm{CBr}$ to give the stabilized adduct, or with CHBr followed by a H-loss. The detection of brominated products suggests that the branching ratio for $\mathrm{Br}$ and/or $\mathrm{HBr}$ elimination is less than unity. Combined with the non-detection of signal at the $\mathrm{m} / \mathrm{z}$ values of the brominated radicals, this suggests that the direct contribution of the $\mathrm{CBr}$ and $\mathrm{CHBr}$ reactions to signals at $\mathrm{m} / \mathrm{z}$ corresponding $\mathrm{CH}$ reaction products is therefore expected to be small. 
Successive reactions of the primary products with remaining radicals in the flow may lead to the formation of secondary products over the experimental reaction time. Because the reactions of $\mathrm{CH}$ with ammonia and amines are very fast, ${ }^{14}$ it is possible to discriminate between primary and secondary reactions by inspecting the product temporal profiles. Figure S1 displays typical kinetic traces obtained when irradiating a mixture of bromoform and MA in helium and nitrogen. The fast rise of the signals at $\mathrm{m} / \mathrm{z} 42,43$, and 57 indicates that these products are likely to be formed by a fast reaction while the slower rise observed at $\mathrm{m} / \mathrm{z} 58$ suggests that the corresponding product is from a slower or secondary reaction. In this section photoinzation spectra are integrated over the 0-40 ms time range, whereas mass spectra integrations are restricted to $0-5 \mathrm{~ms}$ in order to minimize contribution from secondary or slower reactions. Products showing initial formation rates of less than $500 \mathrm{~s}^{-1}$ are assigned to secondary reactions and are not discussed further.

Time- and energy-resolved mass spectra are recorded by averaging at least 500 laser shots at each VUV photon energy, scanned over at least $1.5 \mathrm{eV}$ with an energy step of $25 \mathrm{meV}$. Ar is used in a gas filter in order to absorb harmonics of the undulator radiation. All the amines used in this work have low absorption cross-sections at $248 \mathrm{~nm}\left(<1 \times 10^{-19} \mathrm{~cm}^{2}\right.$ for MA and DMA, $\sim 1 \times 10^{-18} \mathrm{~cm}^{2}$ for TMA $)^{60-62}$ leading to negligible dissociation of MA and DMA and less $6 \%$ dissociation for TMA. Nonetheless, mass spectra of the $\mathrm{NH}_{3}$, MA, DMA where systematically recorded with and without bromoform in order to confirm that no timedependent signal was observed at the masses of the expected $\mathrm{CH}+$ amine reaction products. Although no background was recorded in the case of TMA, time resolved signal observed at $\mathrm{m} / \mathrm{z} 58$ is attributed to TMA photodissociation.

In the following sections, isomer products are identified based on their ionization energy and photoionization spectra. When experimental values are not available, the isomers are identified using the CBS-QB3 calculated ionization energies displayed in Table 1. The 
difference of ionization energies between the $\mathrm{C}_{2} \mathrm{H}_{5} \mathrm{~N}$ cis and trans stereoisomers is found to be less than $0.02 \mathrm{eV}$ and the isomer identification is performed using the trans isomer. The photoion spectra are also fit with integrated experimental or integrated calculated (FranckCondon factors) photoelectron spectra. The predicted spectra for individual isomers are displayed in Figure S1 (supplementary information). The integrated photoelectron spectra ${ }^{63}$ do not distinguish between the cis and trans stereoisomers. The photoelectron spectra for the methyl substituted imines are integrated over the first two vibronic bands of the cation ${ }^{63}$ and normalized to their maximum. Because of the large uncertainties in absolute photoionization cross sections between the different mass channel products, the data are not used to provide reaction product branching fractions. Nonetheless, isomeric branching ratios for a given mass channel are estimated on the assumption that isomers have equal ionization cross sections. ${ }^{64} \mathrm{In}$ the following paragraphs the displayed photoionization spectra for the individual isomers are weighted by their branching ratios.

Table 1. Ioniczation energies of imines and amino carbene isomers calculated using the CBSQB3 method

\begin{tabular}{|c|c|c|c|c|c|c|c|c|c|}
\hline & & \multicolumn{4}{|c|}{ Imines $\mathrm{RN}=\mathrm{CR}^{\prime} \mathrm{R}^{\prime \prime}$} & \multicolumn{4}{|c|}{ Amino carbene RR'N-CR" } \\
\hline Formula & $\mathrm{m} / \mathrm{z}$ & Isomer & IE $(e V)$ & Isomer & $\mathrm{IE}(\mathrm{eV})$ & Isomer & IE $(\mathrm{eV})$ & Isomer & $\mathrm{IE}(\mathrm{eV})$ \\
\hline $\mathrm{CH}_{3} \mathrm{~N}$ & 29 & $\underset{H^{\prime}}{\mathrm{N}}=\mathrm{C}_{\mathrm{H}^{\prime}}^{\mathrm{H}}$ & 9.94 & & & 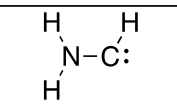 & 8.39 & & \\
\hline $\mathrm{C}_{2} \mathrm{H}_{5} \mathrm{~N}$ & 43 & $\mathrm{H}^{\prime} \mathrm{N}=\mathrm{C}_{\mathrm{C}}^{\mathrm{CH}^{\prime}}$ & $9.54^{(1)}$ & $\mathrm{H}_{3} \mathrm{C}^{\mathrm{N}}$ & 9.13 & $\underbrace{\mathrm{N}-\mathrm{C}^{\prime}:}_{H^{\prime}}$ & 7.65 & 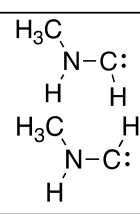 & $\begin{array}{l}7.88 \\
7.84\end{array}$ \\
\hline $\mathrm{C}_{3} \mathrm{H}_{7} \mathrm{~N}$ & 57 & $\begin{array}{r}\mathrm{H}_{3} \mathrm{C}^{\mathrm{N}=\mathrm{C}^{\prime}} \\
\mathrm{H} \\
\mathrm{H}_{3} \mathrm{C}^{\mathrm{N}=\mathrm{C}^{\prime \prime}}{ }^{\prime} \mathrm{Cl}\end{array}$ & $\begin{array}{l}8.83 \\
8.67\end{array}$ & $\mathrm{H}^{\mathrm{N}=\mathrm{C}^{\prime}} \mathrm{CH}^{\mathrm{CH}_{3}}$ & 9.19 & 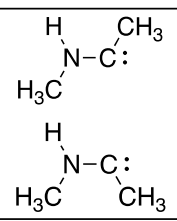 & $\begin{array}{l}7.38 \\
7.18\end{array}$ & $\begin{array}{l}\mathrm{H}_{3} \mathrm{C} \\
\mathrm{H}_{3} \mathrm{C}^{\mathrm{N}}-\mathrm{C}^{\mathrm{H}}\end{array}$ & 7.53 \\
\hline $\mathrm{C}_{4} \mathrm{H}_{9} \mathrm{~N}$ & 71 & $\mathrm{H}_{3} \mathrm{C}^{\mathrm{N}=\mathrm{C}^{\prime}} \mathrm{C}^{\mathrm{C}}$ & 8.42 & & & $\begin{array}{l}\mathrm{H}_{3} \mathrm{C} \\
\text { N- } \mathrm{CH}^{\mathrm{CH}_{3}} \\
\mathrm{H}_{3} \mathrm{C}^{\prime}\end{array}$ & 6.91 & & \\
\hline
\end{tabular}

(1)Cis and trans isomers 


\section{1 $\mathrm{CH}+\mathrm{NH}_{3}$}

Two H-loss exit channels of the $\mathrm{CH}+\mathrm{NH}_{3}$ reaction (R1) are possible, producing the imine $\mathrm{HN}=\mathrm{CH}_{2}$ and the amino carbene $\mathrm{H}_{2} \mathrm{~N}-\mathrm{CH}$ through channels $\mathrm{R} 1 \mathrm{a}$ and $\mathrm{R} 1 \mathrm{~b}$, respectively. The only other exothermic reaction exit channel predicted by Blitz et al. ${ }^{15}$ is the formation of $\mathrm{CH}_{3}$ $+\mathrm{NH}$.

$$
\begin{array}{clll}
\mathrm{CH}+\mathrm{NH}_{3} \rightarrow & \mathrm{HN}=\mathrm{CH}_{2}+\mathrm{H} & -244.44 \mathrm{~kJ} \cdot \mathrm{mol}^{-1} & \mathrm{R} 1 \mathrm{a} \\
& \mathrm{H}_{2} \mathrm{~N}-\mathrm{CH}+\mathrm{H} & -94.96 \mathrm{~kJ} \cdot \mathrm{mol}^{-1} & \mathrm{R} 1 \mathrm{~b} \\
\mathrm{CH}_{3}+\mathrm{NH} & -29.4 \mathrm{~kJ} \cdot \mathrm{mol}^{-1} & \mathrm{R}^{-1} \mathrm{c}^{15}
\end{array}
$$

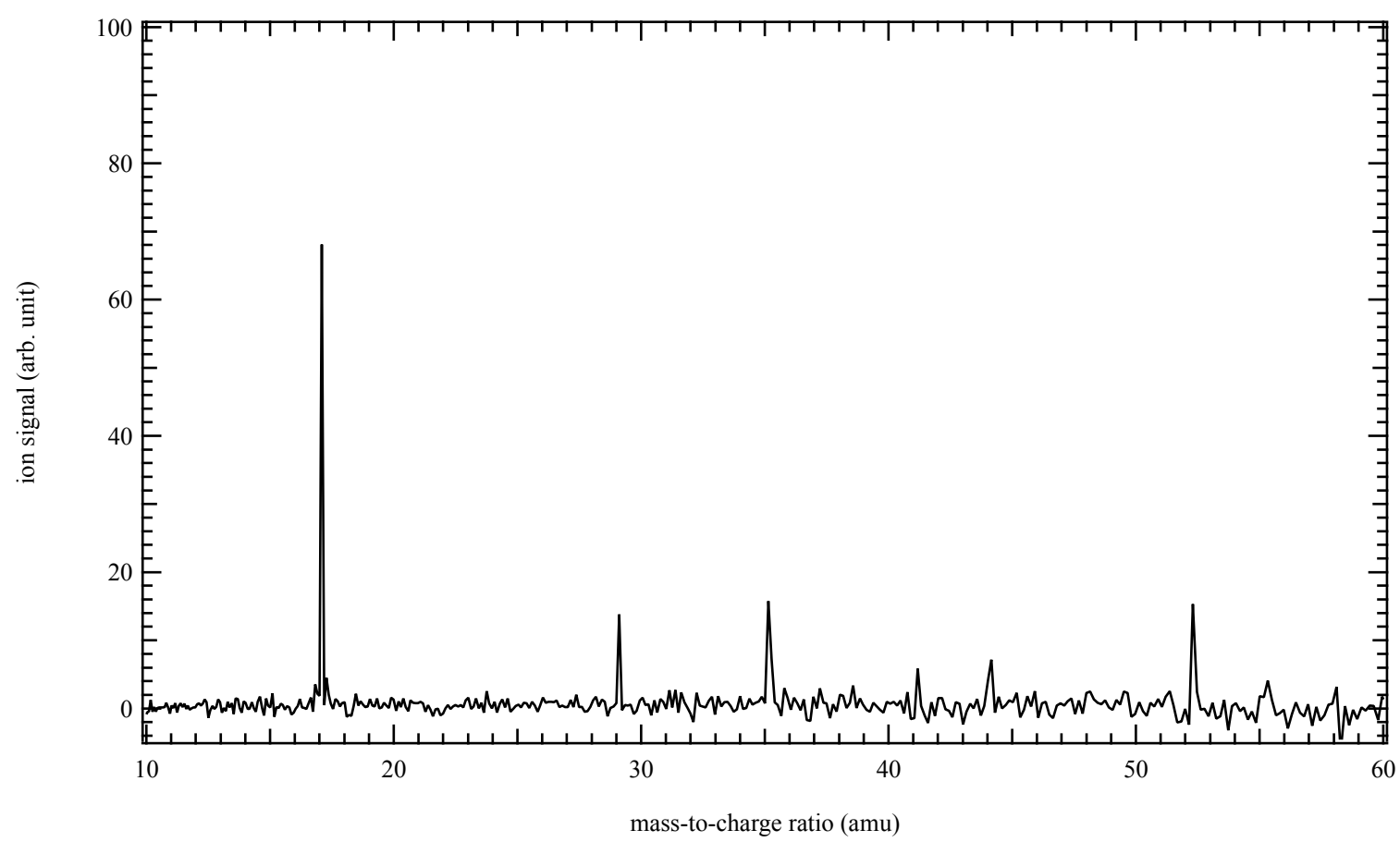

Figure 1. Mass spectrum obtained by photolysis of a $\mathrm{CHBr}_{3}$ and $\mathrm{NH}_{3}$ mixture in helium and nitrogen integrated over the 9.8-10.6 eV photon energy and the 0-5 ms time range.

Figure 1 displays the mass spectrum obtained by photolysis of a $\mathrm{CHBr}_{3}$ and $\mathrm{NH}_{3}$ mixture in helium integrated over the $9.8-10.6 \mathrm{eV}$ photon energy and the $0-5 \mathrm{~ms}$ time range. The large signal at $\mathrm{m} / \mathrm{z} 17$ is likely due to fluctuations in the ammonia signal leading to a remaining positive signal after background subtraction. The main signals are observed at $\mathrm{m} / \mathrm{z} 29,35$, and 52. The signal at $\mathrm{m} / \mathrm{z} 29$ displays a fast rise immediately after the laser pulse, as expected for a 
$\mathrm{CH}+\mathrm{NH}_{3}$ reaction product. The temporal profiles of $\mathrm{m} / \mathrm{z} 35$ and 52 show a sharp signal rise starting about $4 \mathrm{~ms}$ after the laser pulse and displaying a rapid decay over the following $5 \mathrm{~ms}$. Although the origin of these two signals is undetermined, $\mathrm{NH}_{3} \cdot \mathrm{H}_{2} \mathrm{O}$ and $2 \mathrm{NH}_{3} \cdot \mathrm{H}_{2} \mathrm{O}$ are the only species that match the observed $\mathrm{m} / \mathrm{z}$ values. The formation of these clusters at $373 \mathrm{~K}$ is not favorable and the observed ions are more likely to come from dissociative ionization of higher mass neutral species. Additional signals (not shown here) are observed at $\mathrm{m} / \mathrm{z} 79,81$, 104, and 106 corresponding to $\mathrm{Br}$ atoms and brominated compounds. The photoion signal at $\mathrm{m} / \mathrm{z} 104$ and 106 has a fast kinetic rise and shows an ion onset at about $10.3 \mathrm{eV}$ corresponding to the photoionization energy of bromoacetylene. ${ }^{65}$ Although there is no clear pathway leading to $\mathrm{BrCCH}$ formation in the reaction flow, its formation does not interfere with the detection of $\mathrm{CH}+\mathrm{NH}_{3}$ products. From this analysis, it is concluded that only the signal at $\mathrm{m} / \mathrm{z} 29$ originates from the $\mathrm{CH}+\mathrm{NH}_{3}$ reaction.

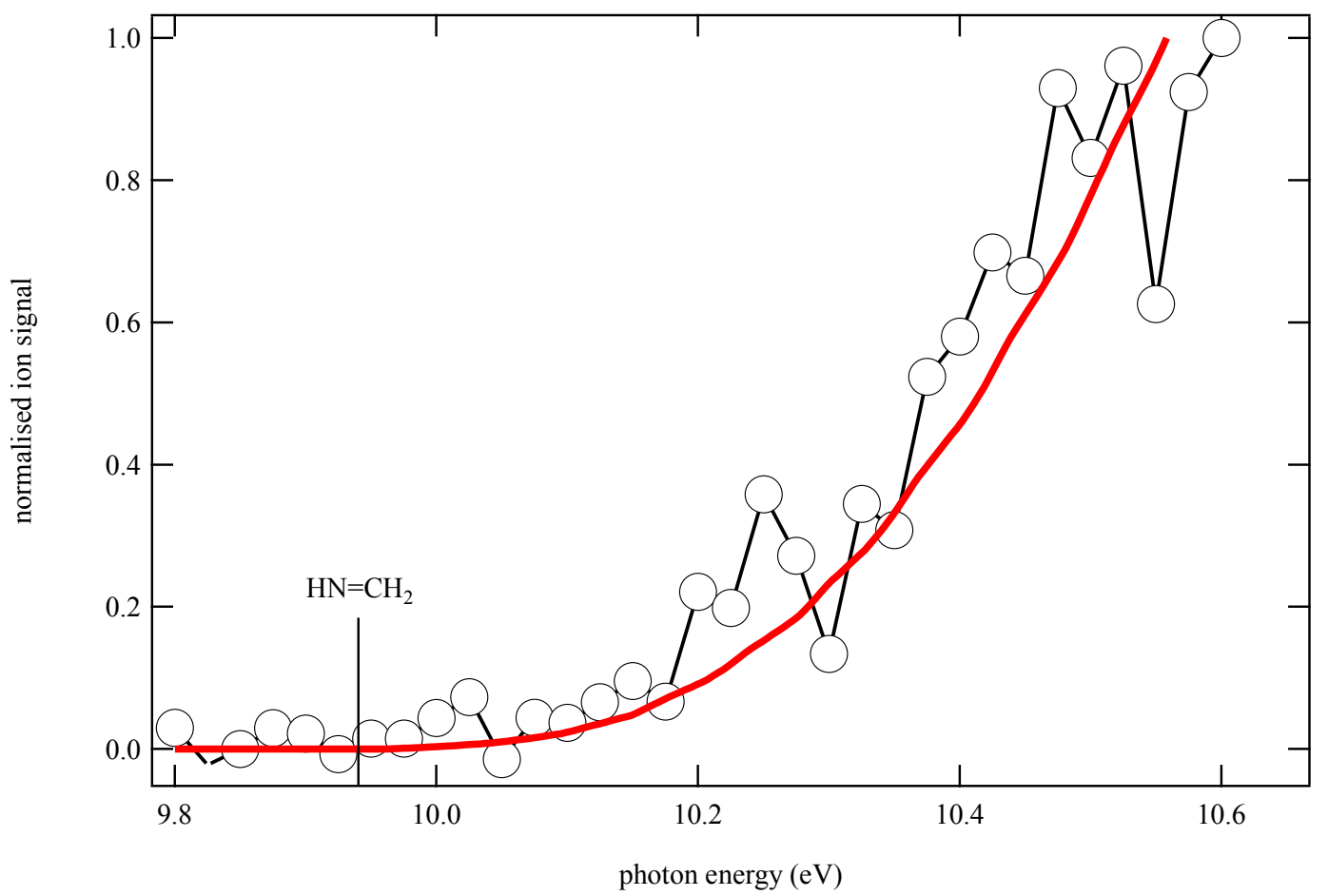

Figure 2. Photoionization spectrum of $\mathrm{m} / \mathrm{z} 29$ (open circles) obtained by photolysis of a $\mathrm{CHBr}_{3}$ and $\mathrm{NH}_{3}$ mixture in helium and nitrogen integrated over the $0-40 \mathrm{~ms}$ time range and displayed from 9.8 to $10.6 \mathrm{eV}$ photon energy. The vertical line denotes the experimental ionization energy 
of $\mathrm{HN}=\mathrm{CH}_{2} \cdot{ }^{63}$ The thick red line is the integrated experimental photoelectron spectrum of $\mathrm{HN}=\mathrm{CH}_{2}$ from Bock et al. ${ }^{63}$

Figure 2 displays the photoionization spectrum of $\mathrm{m} / \mathrm{z} 29$ integrated over the $0-40 \mathrm{~ms}$ time range. The good match between the experimental data (open circles) and the integrated experimental photoelectron spectrum of $\mathrm{HN}=\mathrm{CH}_{2}$ (red thick line) from Bock et al. ${ }^{63}$ confirms the formation of $\mathrm{HN}=\mathrm{CH}_{2}$ in the reaction flow. As displayed in Table 1 the calculated $\mathrm{H}_{2} \mathrm{~N}-$ $\mathrm{CH}$ amino carbene ionization energy is $8.39 \mathrm{eV}$, well below that of the $\mathrm{HN}=\mathrm{CH}_{2}$ isomer. The absence of signal below $9.9 \mathrm{eV}$ confirms that the amino carbene isomer $\mathrm{H}_{2} \mathrm{~N}-\mathrm{CH}$ is not formed in the reaction flow and that only R1a contributes to the reaction mechanism. Additional experiments were performed with deuterated bromoform as the radical precursor in order to provide information on isomerization pathways. The main $\mathrm{CD}+\mathrm{NH}_{3}$ product signal is observed at $\mathrm{m} / \mathrm{z} 30$ with no significant signal at $\mathrm{m} / \mathrm{z} 29$, indicating an absence of $\mathrm{D}$ loss from the initial adduct. The photoionization spectrum of $\mathrm{m} / \mathrm{z} 30$ is identical to that of $\mathrm{m} / \mathrm{z} 29$ from the $\mathrm{CH}+\mathrm{NH}_{3}$ reaction.

\section{$4.2 \mathrm{CH}+\mathrm{CH}_{3} \mathrm{NH}_{2}$}

The reaction of the $\mathrm{CH}$ radical with MA (R2) may proceed both by $\mathrm{H}-(\mathrm{R} 2 \mathrm{a}, \mathrm{b}$, c, and d) or $\mathrm{CH}_{3}$-loss (R2e and f) to form imines (R2a, b, and e) or amino carbenes (R2c, d, and f) at $\mathrm{m} / \mathrm{z}$ 43 and 29. The enthalpy of reaction for producing trans- vs. cis- $\mathrm{HN}=\mathrm{CHCH}_{3}$ or trans- vs. cis$\mathrm{CH}_{3} \mathrm{HN}-\mathrm{CH}$ stereoisomers differs by less than $3 \mathrm{~kJ} \mathrm{~mol}^{-1}$; the enthalpies of reaction given in $\mathrm{R} 2 \mathrm{a}$ and $\mathrm{R} 2 \mathrm{c}$ are for the trans isomers. All the exit pathways are exothermic with formation of the imines being at least $100 \mathrm{~kJ} \cdot \mathrm{mol}^{-1}$ more exothermic than the amino carbenes.

$$
\begin{aligned}
& \mathrm{CH}+\mathrm{CH}_{3} \mathrm{NH}_{2} \rightarrow \quad \mathrm{HN}=\mathrm{CHCH}_{3}(\mathrm{~m} / \mathrm{z} 43)+\mathrm{H} \quad-313.17 \mathrm{~kJ} \cdot \mathrm{mol}^{-1} \quad \mathrm{R} 2 \mathrm{a} \\
& \mathrm{CH}_{3} \mathrm{~N}=\mathrm{CH}_{2}(\mathrm{~m} / \mathrm{z} 43)+\mathrm{H} \quad-277.36 \mathrm{~kJ} \cdot \mathrm{mol}^{-1} \quad \mathrm{R} 2 \mathrm{~b} \\
& \mathrm{CH}_{3} \mathrm{HN}-\mathrm{CH}(\mathrm{m} / \mathrm{z} 43)+\mathrm{H} \quad-128.99 \mathrm{~kJ} \cdot \mathrm{mol}^{-1} \quad \mathrm{R} 2 \mathrm{c} \\
& \mathrm{H}_{2} \mathrm{~N}-\mathrm{CCH}_{3}(\mathrm{~m} / \mathrm{z} 43)+\mathrm{H} \quad-168.82 \mathrm{~kJ} \cdot \mathrm{mol}^{-1} \quad \mathrm{R} 2 \mathrm{~d}
\end{aligned}
$$




$$
\begin{array}{llllll}
\mathrm{HN}=\mathrm{CH}_{2} & (\mathrm{~m} / \mathrm{z} 29)+\mathrm{CH}_{3} & -251.30 \mathrm{~kJ} \cdot \mathrm{mol}^{-1} & \mathrm{R} 2 \mathrm{e} \\
\mathrm{H}_{2} \mathrm{~N}-\mathrm{CH} & (\mathrm{m} / \mathrm{z} 29)+\mathrm{CH}_{3} & -101.82 \mathrm{~kJ} \cdot \mathrm{mol}^{-1} & \mathrm{R} 2 \mathrm{f}
\end{array}
$$

Figure 3 displays the photoionization spectrum of $\mathrm{m} / \mathrm{z} 29$ (open circles) obtained by photolysis of a $\mathrm{CHBr}_{3}$ and $\mathrm{CH}_{3} \mathrm{NH}_{2}$ mixture in helium and nitrogen integrated over the $0-40 \mathrm{~ms}$ time range. The thick red line is the integrated photoelectron spectrum of $\mathrm{HN}=\mathrm{CH}_{2}$ from Bock et $a l .{ }^{63}$ The good match between the experimental data and the integrated photoelectron spectrum as well as the absence of signal below $9.9 \mathrm{eV}$ suggest that only the imine isomer is formed in the reaction flow.

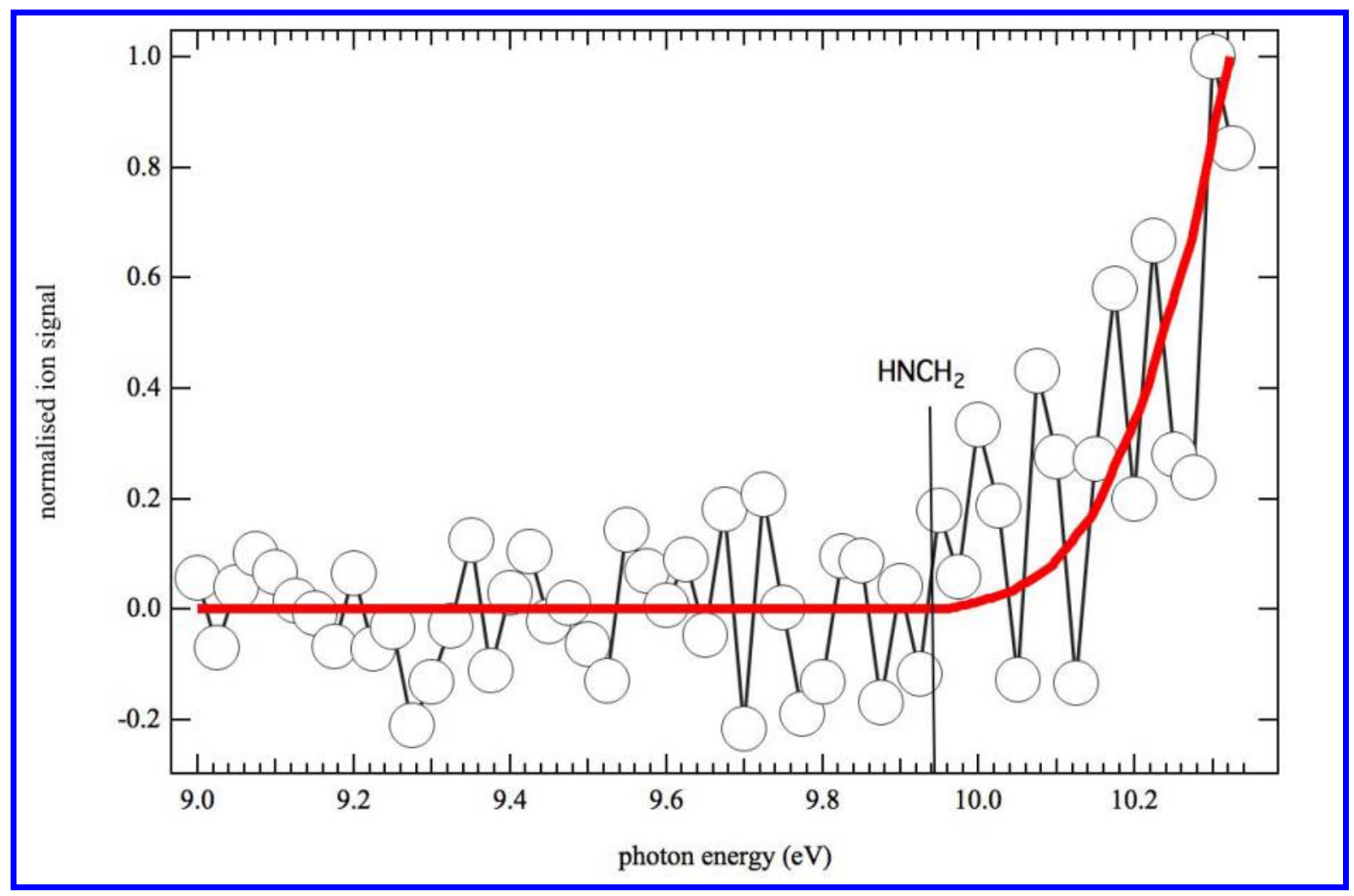

Figure 3. Photoionization spectrum of $\mathrm{m} / \mathrm{z} 29$ (open circles) obtained by photolysis of a $\mathrm{CHBr}_{3}$ and $\mathrm{CH}_{3} \mathrm{NH}_{2}$ mixture in helium and nitrogen integrated over the $0-40 \mathrm{~ms}$ time range and displayed from 9.0 to $10.3 \mathrm{eV}$ photon energy. The thick red line is the integrated photoelectron spectrum of $\mathrm{HN}=\mathrm{CH}_{2}$ from Bock et al. ${ }^{63}$

Figure 4 displays the photoion signal at m/z 15 (open circles) integrated over the $0-40 \mathrm{~ms}$ time range obtained by photolysis of a $\mathrm{CHBr}_{3}$ and $\mathrm{CH}_{3} \mathrm{NH}_{2}$ mixture. The data is superposed to the 
experimental spectrum of the methyl radical (red line). ${ }^{66}$ The good match confirms the formation of $\mathrm{CH}_{3}$ radical in the reaction flow.

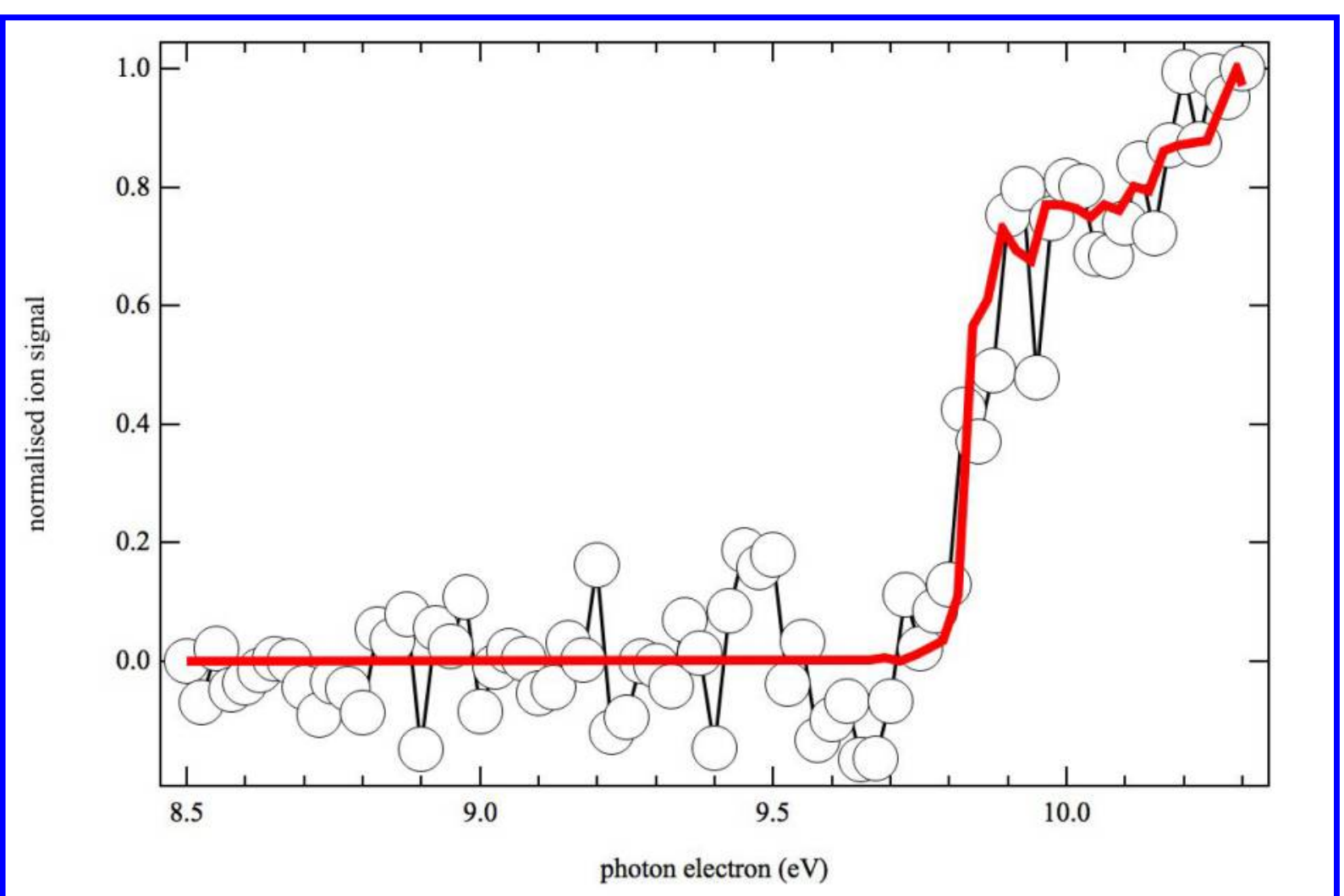

Figure 4. Photoion signal at $\mathrm{m} / \mathrm{z} 15$ (open circles) integrated over the $0-40 \mathrm{~ms}$ time range obtained by photolysis of a $\mathrm{CHBr}_{3}$ and $\mathrm{CH}_{3} \mathrm{NH}_{2}$ mixture in helium and nitrogen displayed from 8.5 to $10.3 \mathrm{eV}$ photon energy. The thick red line is the absolute spectrum (solid red line) of the methyl radical $\left(\mathrm{CH}_{3}\right)$ obtained by Savee et al. ${ }^{66}$

Figure 5 displays the photoionization spectra obtained at $\mathrm{m} / \mathrm{z} 43$ recorded under the same experimental conditions as those of Figures 3 and 4 . The purple solid line is a fit to the data using normalized integrated photoelectron spectra of two methylimine isomers: $\mathrm{CH}_{3} \mathrm{~N}=\mathrm{CH}_{2}$ (blue dashed line) and $\mathrm{HN}=\mathrm{CHCH}_{3}$ (red dotted line), ${ }^{63}$ assuming equal photoionization cross sections after the first two vibronic bands. The fit to the data returns a $\mathrm{CH}_{3} \mathrm{~N}=\mathrm{CH}_{2}: \mathrm{HN}=\mathrm{CHCH}_{3}$ branching ratio of $0.9: 1$. The absence of onset at the ionization energy of the $\mathrm{CH}_{3} \mathrm{~N}=\mathrm{CH}_{2}$ is likely due to the poor Franck-Condon overlap between the neutral and cation vibronic ground states. 


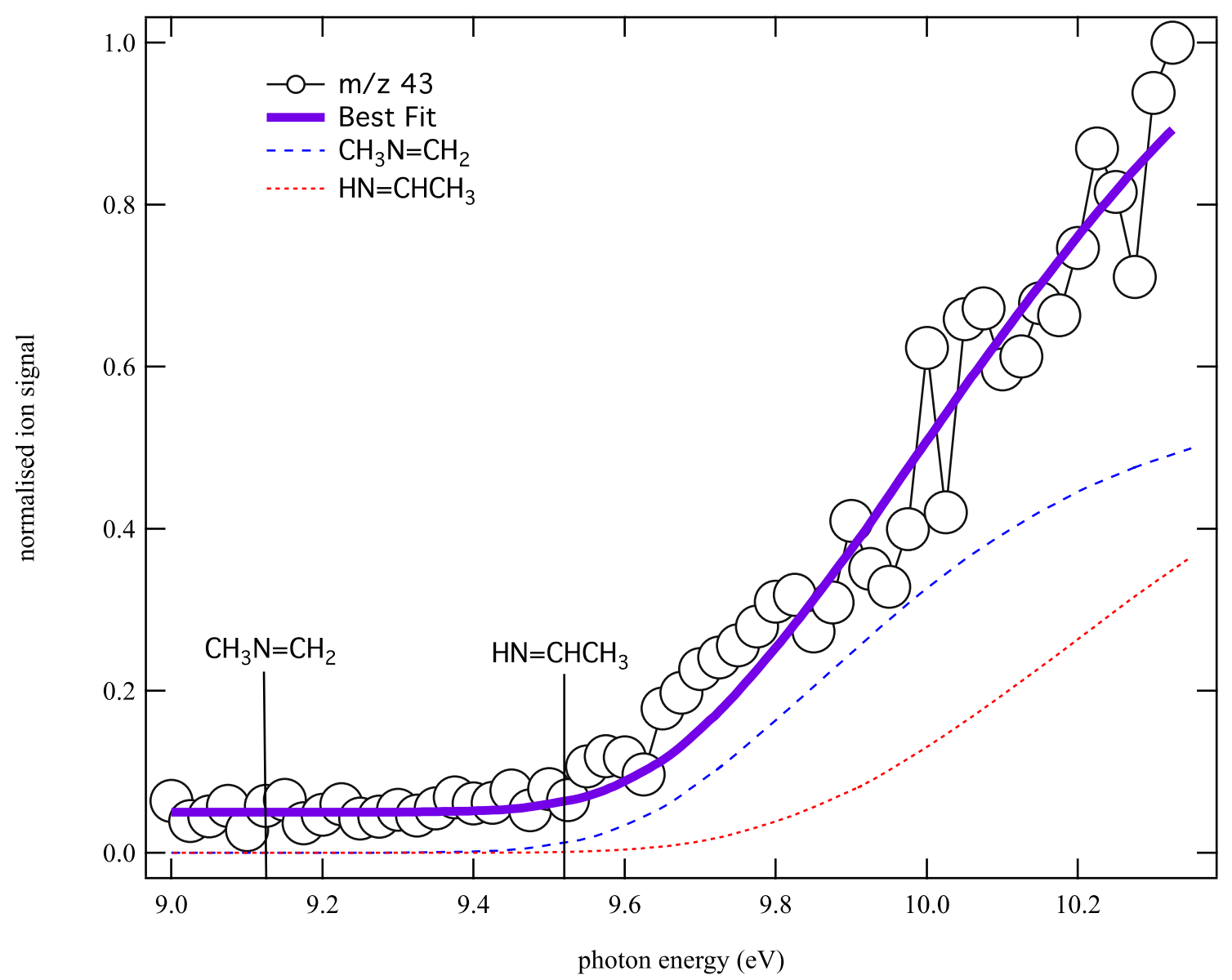

Figure 5. Photoionization spectrum at $\mathrm{m} / \mathrm{z} 43$ (open circles) obtained by photolysis of a $\mathrm{CHBr}_{3}$ and $\mathrm{CH}_{3} \mathrm{NH}_{2}$ mixture in helium and nitrogen integrated over the $0-40 \mathrm{~ms}$ time range. The purple solid line is a fit to the data using the integrated photoelectron spectra of $\mathrm{CH}_{3} \mathrm{~N}=\mathrm{CH}_{2}$ (blue dashed line), $\mathrm{HN}=\mathrm{CHCH}_{3}$ (red dotted line) from Bock et al. ${ }^{63}$ The best fit to the data is obtained for a $\mathrm{CH}_{3} \mathrm{~N}=\mathrm{CH}_{2}: \mathrm{HN}=\mathrm{CHCH}_{3}$ branching ratio of $0.9: 1$.

In Figure 5, a small ion signal is observed from 9.0 - 9.1 eV, below the energy of both imine isomers. Inspection of the kinetic traces reveals that the corresponding ions are detected only after irradiation of the flow by the laser pulse. This signal below $9.1 \mathrm{eV}$ remains constant after the laser pulse, which is uncharacteristic of reactive carbene molecules. No signals are detected at the $\mathrm{m} / \mathrm{z}$ corresponding to the brominated adducts, and the offset is therefore unlikely to be due to dissociative ionization of higher mass products. The constant signal offset below the energy of the methylimine isomers does not enable us to unequivocally rule out the 
formation of the amino carbene isomers, but should not affect the methylimine branching ratios.

\section{$4.3 \quad \mathrm{CH}+\left(\mathrm{CH}_{3}\right)_{2} \mathrm{NH}$}

The reaction of the $\mathrm{CH}$ radical with dimethyl amine may lead to a total of 8 exothermic exit channels, through H-loss (R3a, a' b, c, and d) and $\mathrm{CH}_{3}$-loss (R3e, f, g, and h). The enthalpy in $\mathrm{R} 3 \mathrm{e}$ is for the trans isomer. As for the reaction with MA, formation of the methyl amino carbenes (R3c, d, g, and h) is found to be less thermodynamically favorable by at least 100 $\mathrm{kJ} . \mathrm{mol}^{-1}$.

$$
\begin{aligned}
& \mathrm{CH}+\left(\mathrm{CH}_{3}\right)_{2} \mathrm{NH} \rightarrow \text { trans }-\mathrm{CH}_{3} \mathrm{~N}=\mathrm{CHCH}_{3}(\mathrm{~m} / \mathrm{z} 57)+\mathrm{H} \quad-325.18 \mathrm{~kJ} \cdot \mathrm{mol}^{-1} \mathrm{R} 3 \mathrm{a} \\
& \text { cis }-\mathrm{CH}_{3} \mathrm{~N}=\mathrm{CHCH}_{3} \quad(\mathrm{~m} / \mathrm{z} 57) \quad+\mathrm{H} \quad-309.193 \mathrm{~kJ} \cdot \mathrm{mol}^{-1} \mathrm{R} 3 \mathrm{a}^{\prime} \\
& \mathrm{HN}=\mathrm{C}\left(\mathrm{CH}_{3}\right)_{2} \quad(\mathrm{~m} / \mathrm{z} 57)+\mathrm{H} \quad-358.53 \mathrm{~kJ} \cdot \mathrm{mol}^{-1} \mathrm{R} 3 \mathrm{~b} \\
& \text { trans }-\mathrm{CH}_{3} \mathrm{HN}-\mathrm{CCH}_{3}(\mathrm{~m} / \mathrm{z} 57)+\mathrm{H} \quad-181.70 \mathrm{~kJ} \cdot \mathrm{mol}^{-1} \mathrm{R} 3 \mathrm{c} \\
& \text { cis }-\mathrm{CH}_{3} \mathrm{HN}-\mathrm{CCH}_{3} \quad(\mathrm{~m} / \mathrm{z} 57)+\mathrm{H} \quad-161.38 \mathrm{~kJ}^{2} \cdot \mathrm{mol}^{-1} \quad \mathrm{R} 3 \mathrm{c}^{\prime} \\
& \left(\mathrm{CH}_{3}\right)_{2} \mathrm{~N}-\mathrm{CH} \quad(\mathrm{m} / \mathrm{z} 57)+\mathrm{H} \quad-142.55 \mathrm{~kJ}^{2} \cdot \mathrm{mol}^{-1} \mathrm{R} 3 \mathrm{~d} \\
& \mathrm{HN}=\mathrm{CHCH}_{3} \quad(\mathrm{~m} / \mathrm{z} 43) \quad+\mathrm{CH}_{3} \quad-300.33 \mathrm{~kJ} \cdot \mathrm{mol}^{-1} \quad \mathrm{R} 3 \mathrm{e} \\
& \mathrm{CH}_{3} \mathrm{~N}=\mathrm{CH}_{2} \quad(\mathrm{~m} / \mathrm{z} 43)+\mathrm{CH}_{3}-264.53 \mathrm{~kJ} \cdot \mathrm{mol}^{-1} \mathrm{R} 3 \mathrm{f} \\
& \text { trans }-\mathrm{CH}_{3} \mathrm{HN}-\mathrm{CH} \quad(\mathrm{m} / \mathrm{z} 43)+\mathrm{CH}_{3}-116.16 \mathrm{~kJ} \cdot \mathrm{mol}^{-1} \mathrm{R} 3 \mathrm{~g} \\
& \text { cis- } \mathrm{CH}_{3} \mathrm{HN}-\mathrm{CH} \quad(\mathrm{m} / \mathrm{z} 43)+\mathrm{CH}_{3}-112.52 \mathrm{~kJ} \cdot \mathrm{mol}^{-1} \quad \mathrm{R} 3 \mathrm{~g} \text { ' } \\
& \mathrm{H}_{2} \mathrm{~N}-\mathrm{CCH}_{3} \quad(\mathrm{~m} / \mathrm{z} 43)+\mathrm{CH}_{3}-155.99 \mathrm{~kJ} \cdot \mathrm{mol}^{-1} \mathrm{R} 3 \mathrm{~h}
\end{aligned}
$$

Figure 6 displays the mass spectrum obtained by photolysis of a $\mathrm{CHBr}_{3}$ and $\left(\mathrm{CH}_{3}\right)_{2} \mathrm{NH}$ mixture in helium and nitrogen integrated over the $8.5-10.6 \mathrm{eV}$ photon energy and the 0-5 ms time range. The main signals are detected at $\mathrm{m} / \mathrm{z} 15,42,43,57$ and 58 . The signal at $\mathrm{m} / \mathrm{z} 58$ increases more slowly $\left(400 \mathrm{~s}^{-1}\right)$ than the other signals and is likely not a direct product of the $\mathrm{CH}+\mathrm{DMA}$ reaction. The photoion spectrum of $\mathrm{m} / \mathrm{z} 42$ shows an ionization onset at $\sim 9.7 \mathrm{eV}$ with a photoionization spectrum characteristic of propene $\left(\mathrm{C}_{3} \mathrm{H}_{6}\right)$. 


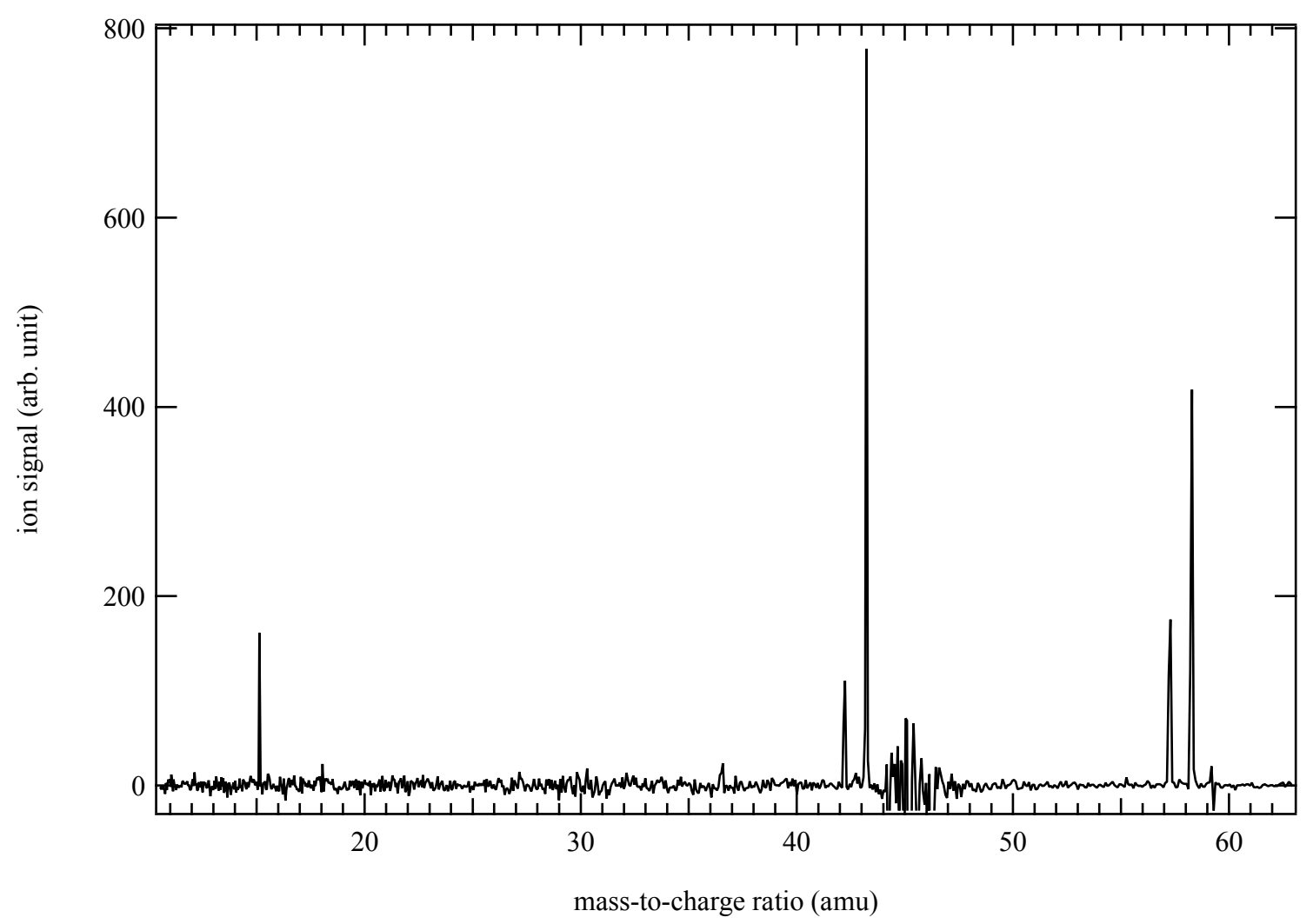

Figure 6. Mass spectrum obtained by photolysis of a $\mathrm{CHBr}_{3}$ and $\left(\mathrm{CH}_{3}\right)_{2} \mathrm{NH}$ mixture in helium and nitrogen integrated over the $8.5-10.6 \mathrm{eV}$ photon energy and the $0-5 \mathrm{~ms}$ time range.

Figure 7 displays the photoion signal at $\mathrm{m} / \mathrm{z} 43$ (open circles) integrated over the $0-40 \mathrm{~ms}$ time range from the same experiment. The purple solid line is a fit to the data using the integrated photoelectron spectra of $\mathrm{CH}_{3} \mathrm{~N}=\mathrm{CH}_{2}$ (blue dashed line) and $\mathrm{HN}=\mathrm{CHCH}_{3}$ (red dotted line) from Bock et al. ${ }^{63}$ The best fit to the data is obtained for a $\mathrm{CH}_{3} \mathrm{~N}=\mathrm{CH}_{2}: \mathrm{HN}=\mathrm{CHCH}_{3}$ ratio of $0.7: 1$. No ion signal is detected at low energy, suggesting that no methyl amino carbene isomers are formed. The excepted mass 43 co-product, the methyl radical, is detected at $\mathrm{m} / \mathrm{z} 15$ with a photoionization spectrum identical to that displayed in Figure 4. 


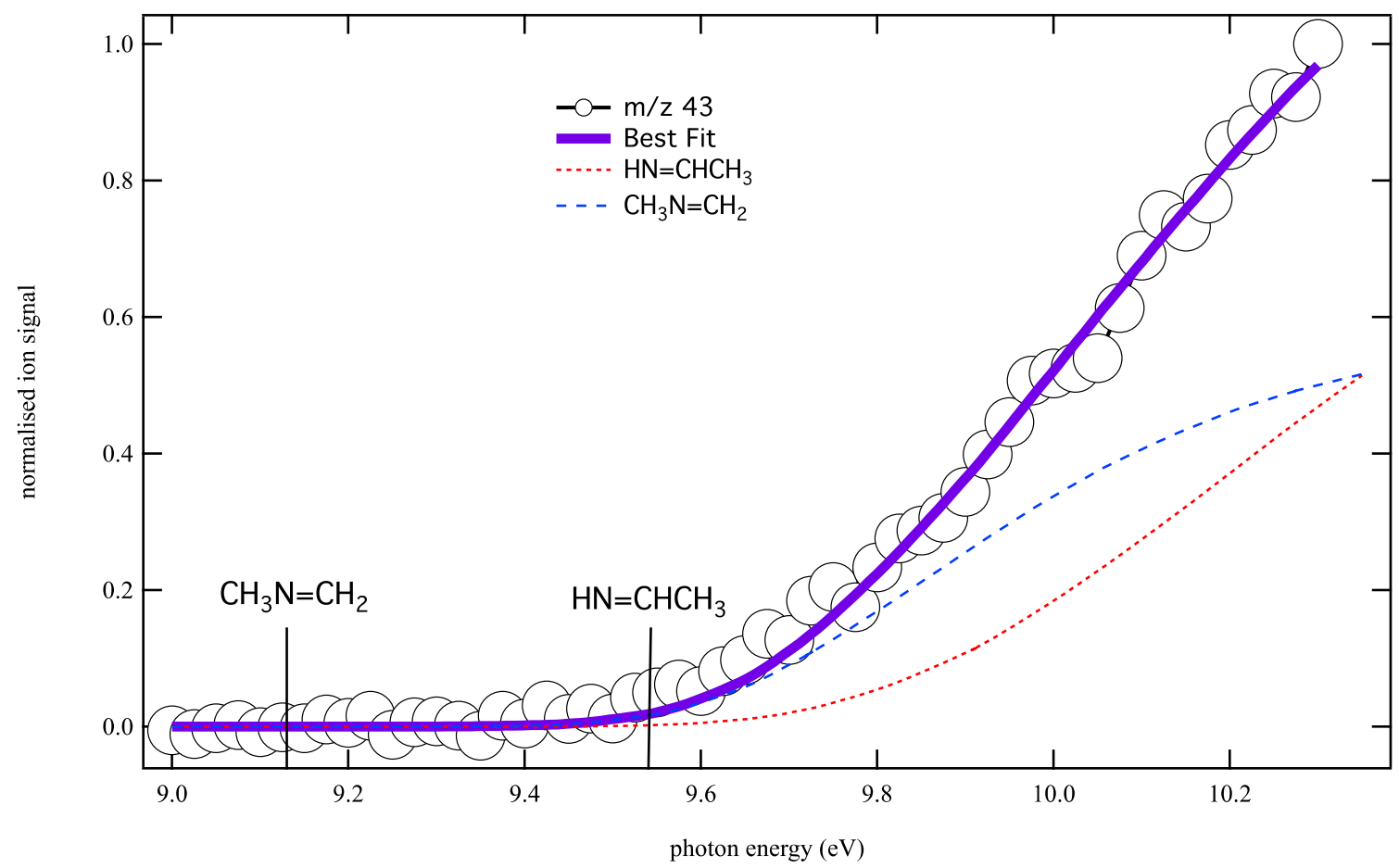

Figure 7. Photoionization spectrum at $\mathrm{m} / \mathrm{z} 43$ (open circles) obtained by photolysis of a $\mathrm{CHBr}_{3}$ and $\left(\mathrm{CH}_{3}\right)_{2} \mathrm{NH}$ mixture in helium and nitrogen integrated over the $0-40 \mathrm{~ms}$ time. The purple solid line is a fit to the data using the integrated photoelectron spectra of $\mathrm{CH}_{3} \mathrm{~N}=\mathrm{CH}_{2}$ (blue dashed line) and $\mathrm{HN}=\mathrm{CHCH}_{3}$ (red dotted line) from Bock et al. ${ }^{63}$ The best fit to the data is obtained for a $\mathrm{CH}_{3} \mathrm{~N}=\mathrm{CH}_{2}: \mathrm{HN}=\mathrm{CHCH}_{3}$ branching ratio of $0.7: 1$.

Figure 8 displays the photoionization spectrum at $\mathrm{m} / \mathrm{z} 57$ (open circles) recorded under the same experimental conditions as those of Figure 6 and 7. The purple solid line is a fit to the data using the integrated photoelectron spectra of $\mathrm{HN}=\mathrm{C}\left(\mathrm{CH}_{3}\right)_{2}$ (red dashed line) from Bock et $a l .{ }^{63}$ as well as integrated Franck-Condon factors for the trans- (blue dotted line) and cis- (blue dotted and dashed line) $\mathrm{CH}_{3} \mathrm{~N}=\mathrm{CHCH}_{3}$ isomers. There is a constant signal offset below the ionization energies of the cis and trans dimethylimine stereoisomers. Although the observed signal could be attributed to the dimethyl amino-carbenes $\mathrm{CH}_{3} \mathrm{HN}-\mathrm{CCH}_{3}$ and $\left(\mathrm{CH}_{3}\right)_{2} \mathrm{~N}-\mathrm{CH}$, the $\mathrm{m} / \mathrm{z} 57$ temporal profile below the energy of the $\mathrm{CH}_{3} \mathrm{~N}=\mathrm{CHCH}_{3}$ dimethylimine isomers displays a constant signal after its formation by the laser pulse. Such time-trace is unlikely for reactive carbene compounds. Signals are also detected at m/z 121/123, 122/124 and 135/137, 
likely corresponding to brominated compounds. No signals are observed at m/z 136/138 or $137 / 139$ values corresponding to the $\mathrm{CHBr} / \mathrm{CBr}+\mathrm{DMA}$ reaction adducts. Dissociative ionization of singly brominated products through $\mathrm{HBr}$ or $\mathrm{H}$ loss is therefore not likely to explain the observed signal offset. Alternatively, the offset could be due to dissociative ionization of $\mathrm{CBr}_{2}$ reaction adducts through $\mathrm{Br}_{2}$ loss. The best fit to the data using a constant offset before the ionization energy of the $\mathrm{CH}_{3} \mathrm{~N}=\mathrm{CHCH}_{3}$ dimethylimine isomers returns a trans $-\mathrm{CH}_{3} \mathrm{~N}=\mathrm{CHCH}_{3}:$ cis- $\mathrm{CH}_{3} \mathrm{~N}=\mathrm{CHCH}_{3}: \mathrm{HN}=\mathrm{C}\left(\mathrm{CH}_{3}\right)_{2}$ of 1:0.2:0.8.

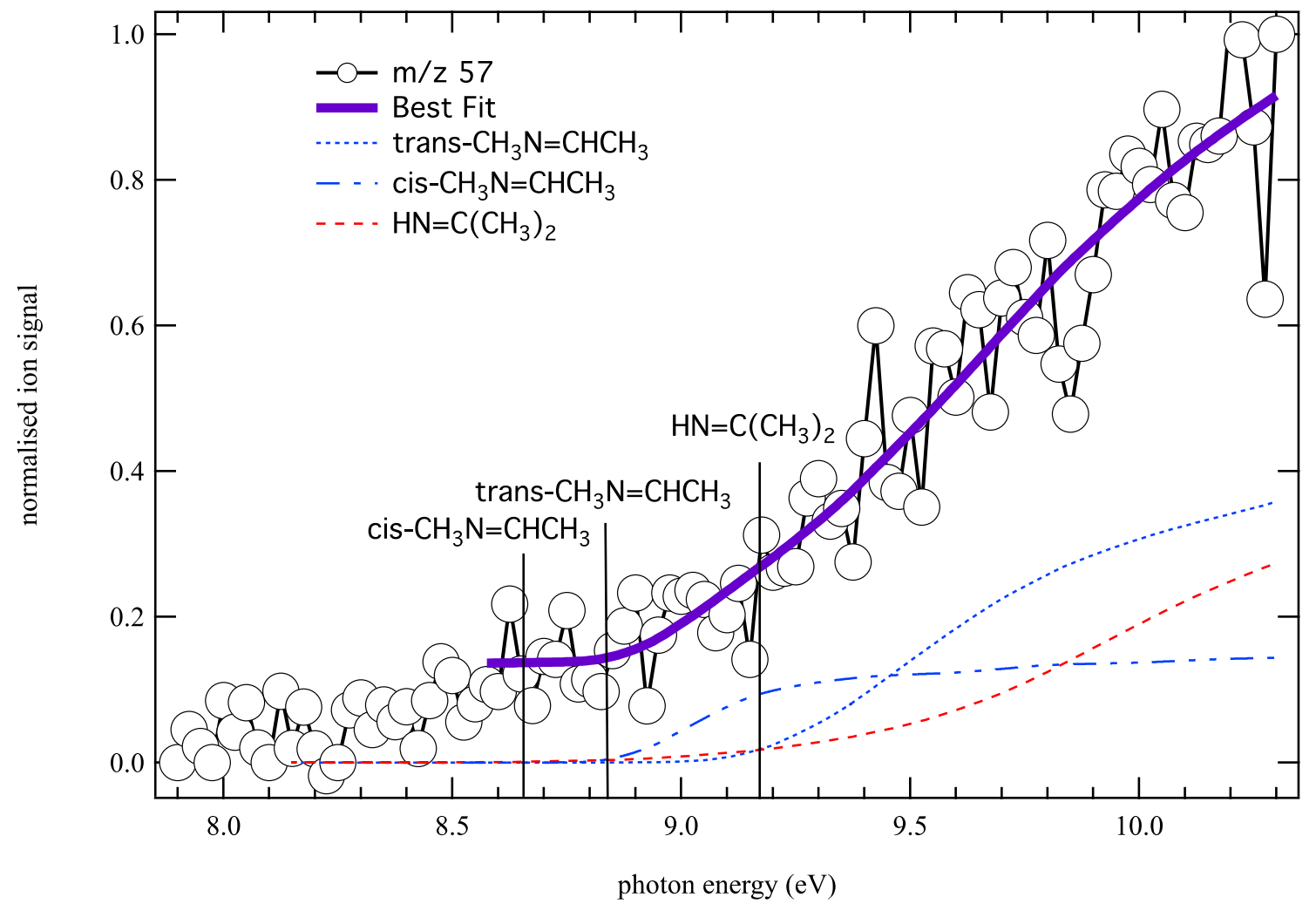

Figure 8. Photoion signal at $\mathrm{m} / \mathrm{z} 57$ (open circles) obtained by photolysis of a $\mathrm{CHBr}_{3}$ and $\left(\mathrm{CH}_{3}\right)_{2} \mathrm{NH}$ mixture in helium and nitrogen integrated over the 0-40 ms time range and displayed from 7.8 to $10.2 \mathrm{eV}$ photon energy. The purple solid line is a fit to the data using the integrated photoelectron spectra of $\mathrm{HN}=\mathrm{C}\left(\mathrm{CH}_{3}\right)_{2}$ (red dashed line) as well as the trans- (blue dotted line) and cis- (blue dotted and dashed line) $\mathrm{CH}_{3} \mathrm{~N}=\mathrm{CHCH}_{3}$. The best fit to the data is obtained for a branching ratio trans- $\mathrm{CH}_{3} \mathrm{~N}=\mathrm{CHCH}_{3}:$ cis- $\mathrm{CH}_{3} \mathrm{~N}=\mathrm{CHCH}_{3}: \mathrm{HN}=\mathrm{C}\left(\mathrm{CH}_{3}\right)_{2}$ of 1:0.2:0.8 


\section{4 $\mathrm{CH}+\left(\mathrm{CH}_{3}\right)_{3} \mathrm{~N}$}

The 6 most likely exit channels for the $\mathrm{CH}$ reaction with TMA are formation of the fully methyl substituted imine and amino carbene, detected at $\mathrm{m} / \mathrm{z} 71$ (R4a, and $\mathrm{b}$ ), as well as the dimethylimines (R4c, c' and d) and dimethyl amino carbenes (R4e and f) at $\mathrm{m} / \mathrm{z} 57$. The enthalpies in $\mathrm{R} 4 \mathrm{~g}$ and $\mathrm{R} 4 \mathrm{i}$ are for the trans isomers. Formation of the methyl substituted imines or amino carbene, detected at $\mathrm{m} / \mathrm{z} 43$, by loss of a $\mathrm{C}_{2} \mathrm{H}_{5}$ radical are also exothermic.

\begin{tabular}{|c|c|c|c|c|}
\hline $\mathrm{CH}+\left(\mathrm{CH}_{3}\right)_{3} \mathrm{~N} \rightarrow$ & $\mathrm{CH}_{3} \mathrm{~N}=\mathrm{C}\left(\mathrm{CH}_{3}\right)_{2}$ & $+\mathrm{H}$ & $-339.62 \mathrm{~kJ} . \mathrm{mol}^{-1}$ & $\mathrm{R} 4 \mathrm{a}$ \\
\hline & $\left(\mathrm{CH}_{3}\right)_{2} \mathrm{~N}-\mathrm{CCH}_{3}$ & $+\mathrm{H}$ & $-158.76 \mathrm{~kJ} . \mathrm{mol}^{-1}$ & $\mathrm{R} 4 \mathrm{~b}$ \\
\hline & trans $-\mathrm{CH}_{3} \mathrm{~N}=\mathrm{CHCH}_{3}$ & $+\mathrm{CH}_{3}$ & $-295.73{\mathrm{~kJ} . \mathrm{mol}^{-1}}^{-1}$ & $\mathrm{R} 4 \mathrm{c}$ \\
\hline & cis- $\mathrm{CH}_{3} \mathrm{~N}=\mathrm{CHCH}_{3}$ & $+\mathrm{CH}_{3}$ & $-279.73 \mathrm{~kJ} \cdot \mathrm{mol}^{-1}$ & $\mathrm{R} 4 \mathrm{c}$ \\
\hline & $\mathrm{HN}=\mathrm{C}\left(\mathrm{CH}_{3}\right)_{2}$ & $+\mathrm{CH}_{3}$ & $-329.73 \mathrm{~kJ} . \mathrm{mol}^{-1}$ & $\mathrm{R} 4 \mathrm{~d}$ \\
\hline & trans- $\mathrm{CH}_{3} \mathrm{HN}-\mathrm{CCH}_{3}$ & $+\mathrm{CH}_{3}$ & $-152.25 \mathrm{~kJ} \mathrm{~mol}^{-1}$ & $\mathrm{R} 4 \mathrm{e}$ \\
\hline & cis- $\mathrm{CH}_{3} \mathrm{HN}-\mathrm{CCH}_{3}$ & $+\mathrm{CH}_{3}$ & $-131.93 \mathrm{~kJ}^{\mathrm{mol}} \mathrm{mol}^{-1}$ & $\mathrm{R} 4 \mathrm{e}$ \\
\hline & $\left(\mathrm{CH}_{3}\right)_{2} \mathrm{~N}-\mathrm{CH}$ & $+\mathrm{CH}_{3}$ & $-113.11 \mathrm{~kJ} . \mathrm{mol}^{-1}$ & $\mathrm{R} 4 \mathrm{f}$ \\
\hline & $\mathrm{HN}=\mathrm{CHCH}_{3}$ & $+\mathrm{C}_{2} \mathrm{H}_{5}$ & $-398.17 \mathrm{~kJ} . \mathrm{mol}^{-1}$ & $\mathrm{R} 4 \mathrm{~g}$ \\
\hline & $\mathrm{CH}_{3} \mathrm{~N}=\mathrm{CH}_{2}$ & $+\mathrm{C}_{2} \mathrm{H}_{5}$ & $-362.35 \mathrm{~kJ} . \mathrm{mol}^{-1}$ & $\mathrm{R} 4 \mathrm{~h}$ \\
\hline & $\mathrm{CH}_{3} \mathrm{HN}-\mathrm{CH}$ & $+\mathrm{C}_{2} \mathrm{H}_{5}$ & - $213.99 \mathrm{~kJ} . \mathrm{mol}^{-1}$ & $\mathrm{R} 4 \mathrm{i}$ \\
\hline & $\mathrm{H}_{2} \mathrm{~N}-\mathrm{CCH}_{3}$ & $+\mathrm{C}_{2} \mathrm{H}_{5}$ & $-253.82 \mathrm{~kJ} . \mathrm{mol}^{-1}$ & $\mathrm{R} 4 \mathrm{j}$ \\
\hline
\end{tabular}




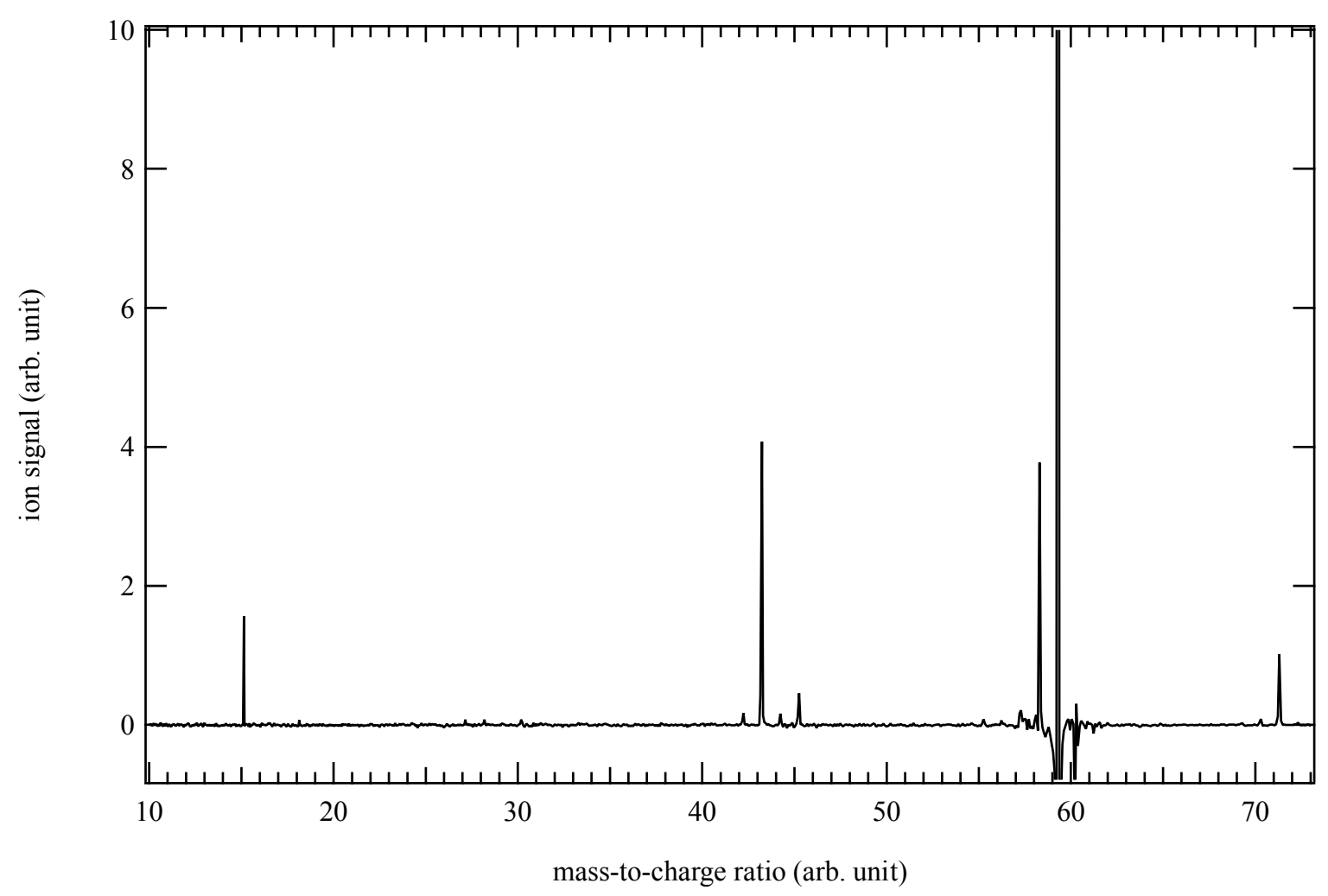

Figure 9. Mass spectrum obtained by photolysis of a $\mathrm{CHBr}_{3}$ and $\left(\mathrm{CH}_{3}\right)_{3} \mathrm{NH}$ mixture in helium and nitrogen integrated over the $8.2-10.3 \mathrm{eV}$ photon energy and the $0-5 \mathrm{~ms}$ time range.

Figure 9 displays the mass spectrum obtained by photolysis of a $\mathrm{CHBr}_{3}$ and $\left(\mathrm{CH}_{3}\right)_{3} \mathrm{~N}$ mixture integrated over the $8.2-10.3 \mathrm{eV}$ photon energy and the $0-5 \mathrm{~ms}$ time range. The main signals are detected at $\mathrm{m} / \mathrm{z} 15,43,58,59$, and 71 . Signal at $\mathrm{m} / \mathrm{z} 59$ is likely to come from the incomplete baseline subtraction of the large TMA signal. As for the reaction with DMA, signal at $\mathrm{m} / \mathrm{z} 15$ is identified as coming from ionization of the methyl radical formed in the reaction flow. Although not as prominent as for reaction $\mathrm{R} 3$, signal at $\mathrm{m} / \mathrm{z} 42$ is identified as propene $(\sim 9.7$ $\mathrm{eV}$. Signal at $\mathrm{m} / \mathrm{z} 58$ displays a fast kinetics and a photoionization spectrum with a lower ionization energy onset $(\sim 8.9 \mathrm{eV})$ than that discussed in Section 4.3 for the bromofrom/DMA mixture at the same $\mathrm{m} / \mathrm{z}$ value. After a fast rise, the signal is found to decay rapidly, within 4 ms after the laser pulse, which is not consistent with the formation of a closed shell molecule 
from the $\mathrm{CH}+\mathrm{TMA}$ reaction. In this case the signal observed at $\mathrm{m} / \mathrm{z} 58$ could come from the dissociative ionization of a higher-mass radical species or direct photodissociation of TMA.

The photoionization spectrum recorded at $\mathrm{m} / \mathrm{z} 43$ for TMA and bromoform is similar to those recorded at the same $\mathrm{m} / \mathrm{z}$ for DMA and bromoform and suggests the formation of $\mathrm{CH}_{3} \mathrm{~N}=\mathrm{CH}_{2}$. No signal is detected at $\mathrm{m} / \mathrm{z} 29$ for the expected $\mathrm{C}_{2} \mathrm{H}_{5}$ coproduct. In the case of the bromoform/TMA mixture, there is a very small signal at m/z 57 (Figure 9), representing less than $10 \%$ of the sum of all the signals at $\mathrm{m} / \mathrm{z} 43,57$ and 71 . Its photoionization spectrum is similar to that displayed in in Figure 8 (open circles). The good match between the two experimental photoion spectra confirms formation of the dimethylimine isomers in the flow, although with a much lower fraction than for the $\mathrm{CH}+$ DMA reaction.

Figure 10 displays photoionization spectrum of m/z 71 (open circles) recorded under the same experimental conditions as Figures 9. A large signal offset is observed below $8.5 \mathrm{eV}$. As for the reaction with MA and DMA, the temporal profile of the ions detected at low energy is constant after their formation upon irradiation by the laser pulse. In the case of reaction with TMA, signals are detected at $\mathrm{m} / \mathrm{z} 150 / 152$ as well as $151 / 153$ possibly corresponding to the $\mathrm{CHBr} / \mathrm{CBr}$ reaction adducts or products. Dissociative ionization of these larger mass molecule may contribute to the observed large signal. The lack of time dependence of the low energy $\mathrm{m} / \mathrm{z} 71$ suggests that the reactive trimethyl amino carbene isomers are not contributing significantly to the $\mathrm{CH}+\mathrm{TMA}$ reaction products. Including a constant offset, the photoionization spectrum in Figure 10 is consistent with the formation of the $\mathrm{CH}_{3} \mathrm{~N}=\mathrm{C}\left(\mathrm{CH}_{3}\right)_{2}$ isomer. 


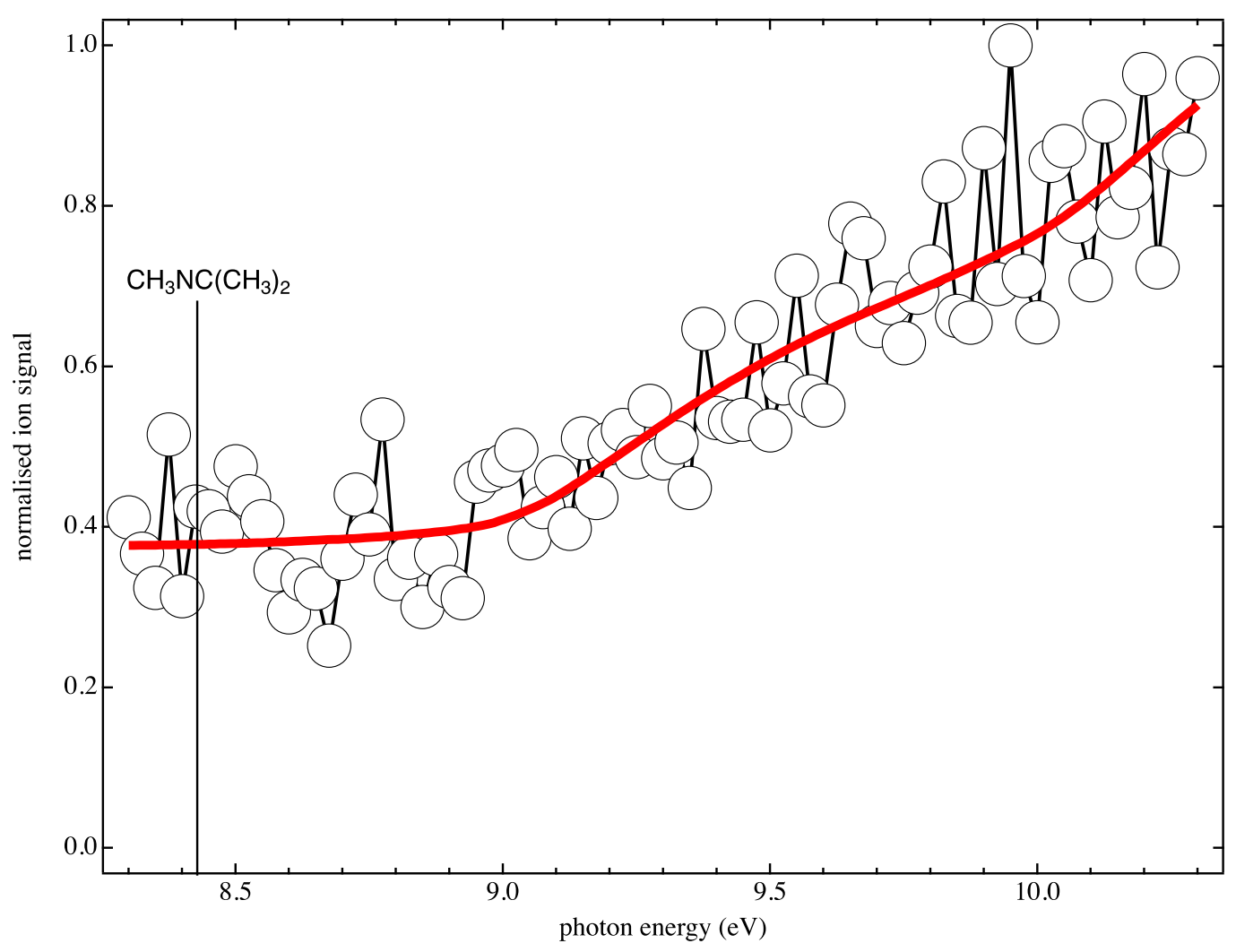

Figure 10. Photoionization spectrum of $\mathrm{m} / \mathrm{z} 71$ (open circles) obtained by photolysis of a $\mathrm{CHBr}_{3}$ and $\left(\mathrm{CH}_{3}\right)_{3} \mathrm{NH}$ mixture in helium and nitrogen integrated over the $0-40 \mathrm{~ms}$ time range. The red solid line is the integrated photoelectron spectra $\mathrm{CH}_{3} \mathrm{~N}=\mathrm{C}\left(\mathrm{CH}_{3}\right)_{2}$ (red dotted line) from Bock et al. ${ }^{63}$.

\section{DISCUSSION}

\subsection{Reaction mechanisms}

The reaction of the $\mathrm{CH}$ radical with $\mathrm{NH}_{3}$ has been studied both experimentally and theoretically. ${ }^{15}$ The MCSCF/CASSCF PES reveals that the initial $\mathrm{H}_{3} \mathrm{~N}-\mathrm{CH}$ complex is formed by a Lewis acid/base-type reaction for which the nitrogen donates electrons to the $\mathrm{CH}$ Lewis acid. This donor-acceptor interaction results in positive and negative charges on the nitrogen and carbon atoms, respectively. A similar mechanism has been proposed for reactions of singlet carbene compounds $\left(\mathrm{CH}_{2}, \mathrm{CHCl}, \mathrm{CHF}\right)$ with amines. ${ }^{67}$ According to the $\mathrm{CH}+\mathrm{NH}_{3} \mathrm{PES},{ }^{15}$ the dative $\mathrm{H}_{3} \mathrm{~N}-\mathrm{CH}$ complex is formed with no energy barrier leading to kinetics mainly controlled by long-range interactions. Scheme 1 displays the mechanism proposed by Blitz et al. ${ }^{15}$ The 
initial $\mathrm{H}_{3} \mathrm{~N}-\mathrm{CH}$ adduct may directly dissociate to $\mathrm{H}_{2} \mathrm{~N}-\mathrm{CH}+\mathrm{H}$ or isomerize through $\mathrm{H}$-atom transfer to form a more stable $\mathrm{H}_{2} \mathrm{~N}-\mathrm{CH}_{2}$ reaction intermediate. The most likely fate of the $\mathrm{H}_{2} \mathrm{~N}-$ $\mathrm{CH}_{2}$ intermediate is dissociation to $\mathrm{HN}=\mathrm{CH}_{2}+\mathrm{H}$, either directly or through a second $\mathrm{H}$-atom transfer followed by $\mathrm{H}$-atom loss. The detection of only $\mathrm{HN}=\mathrm{CH}_{2}$ isomer as a product of the $\mathrm{CH}+\mathrm{NH}_{3}$ reaction in the present study agrees with the $\mathrm{RRKM}-\mathrm{ME}$ branching ratios calculated on the PES by Blitz et al. ${ }^{15}$ in which the $\mathrm{H}-$ loss from the initial $\mathrm{H}_{3} \mathrm{~N}-\mathrm{CH}$ complex is predicted not to be a competitive channel.

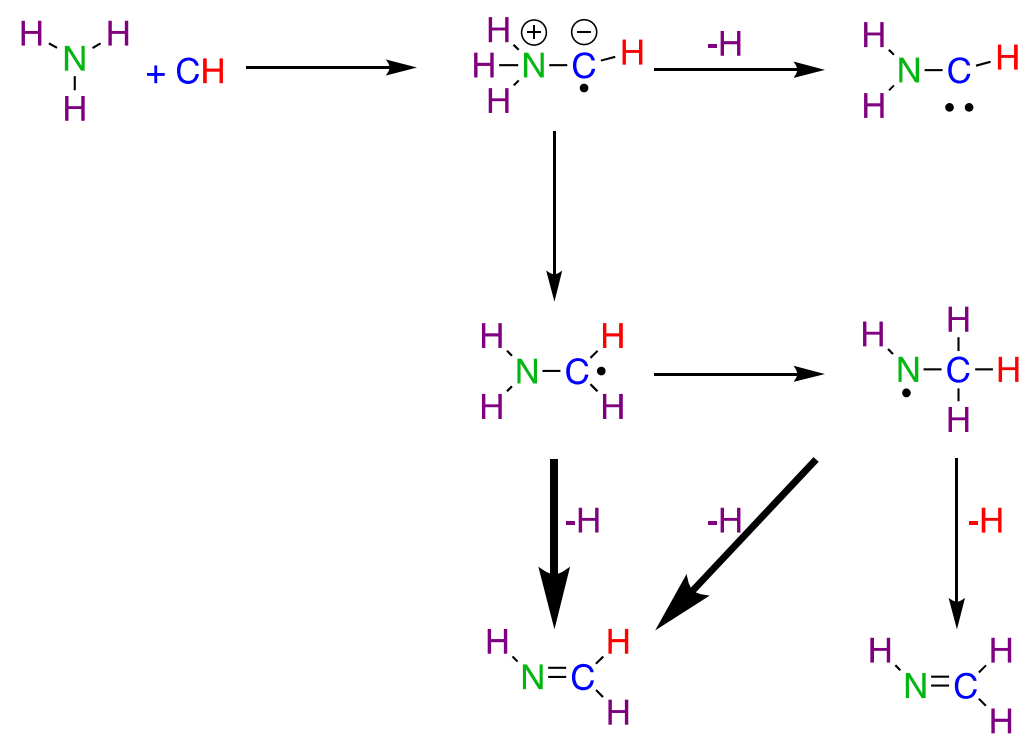

Scheme 1

The only channel leading to the imine $\mathrm{HN}=\mathrm{CH}_{2}$ through elimination of the hydrogen atom initially on the carbon atom involves two successive H-transfers from the nitrogen atom to the carbon atom to form the $\mathrm{HN}-\mathrm{CH}_{3}$ intermediate. In the case of the $\mathrm{CD}+\mathrm{NH}_{3}$ reaction, assuming that the deuteration has no effect on the unimolecular dissociation rate, dissociation of the $\mathrm{HN}-\mathrm{CH}_{2} \mathrm{D}$ intermediate would lead to a 2:1 ratio for $\mathrm{HN}=\mathrm{CHD}: \mathrm{HN}=\mathrm{CH}_{2}$. The detection of mainly $\mathrm{m} / \mathrm{z} 30$ from the $\mathrm{CD}+\mathrm{NH}_{3}$ reaction suggests that the second $\mathrm{H}$ transfer does not compete with the direct dissociation of the $\mathrm{H}_{2} \mathrm{~N}-\mathrm{CHD}$ intermediate. The good agreement between the present work and the RRKM-ME performed on the high-level PES supports the dative-bond mechanism proposed by Blitz et al. for the $\mathrm{CH}+\mathrm{NH}_{3}$ reaction. 
Although there is no theoretical information about the $\mathrm{CH}+\mathrm{NH}_{2} \mathrm{CH}_{3}$ PES, Zabarnick et al. ${ }^{14}$ suggest that the reaction proceeds through insertion of the $\mathrm{CH}$ radical into $\mathrm{N}-\mathrm{H}$ or $\mathrm{C}-$ $\mathrm{H}$ bonds followed by a rapid decomposition of the reaction intermediates. Zabarnick et al. proposed these mechanisms based on the comparison of the measured reaction rate coefficients with those of the $\mathrm{CH}+\mathrm{NH}_{3}$ and $\mathrm{CH}+\mathrm{C}_{2} \mathrm{H}_{6}$ reactions. In view of the PES calculated for the $\mathrm{CH}+\mathrm{NH}_{3},{ }^{15}$ as well as the proposed mechanism for $\mathrm{CH}_{2}, \mathrm{CHF}$, and $\mathrm{CHCl}$ singlet carbene with $\mathrm{MA},{ }^{67}$ it is likely that the reaction may also proceed through the formation of a dative intermediate. Direct insertion into a $\mathrm{C}-\mathrm{H}$ bond of the methyl group is likely to be a minor entrance channel as observed for unsaturated hydrocarbons. ${ }^{40}$

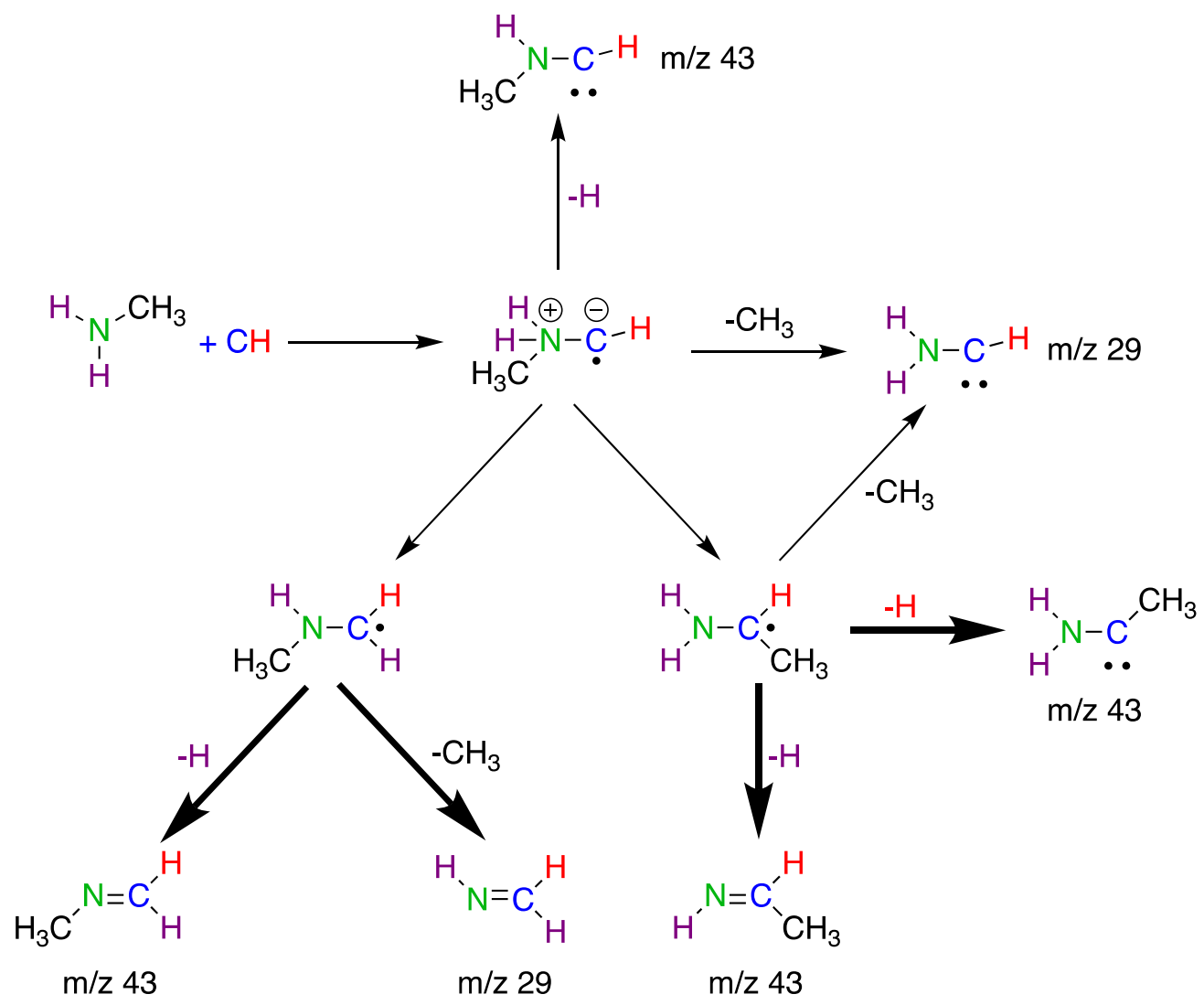

Scheme 2

Scheme 2 displays a proposed mechanism for the $\mathrm{CH}+\mathrm{CH}_{3} \mathrm{NH}_{2}$ reaction starting from the formation of the dative $\mathrm{CH}_{3} \mathrm{H}_{2} \mathrm{~N}-\mathrm{CH}$ intermediate. Bold arrows correspond to observed channels. The detection of $\mathrm{m} / \mathrm{z} \mathrm{15,29}$, and 43 supports the fact that the reaction proceeds 
through both $\mathrm{H}$ - and $\mathrm{CH}_{3}$-loss. We have no evidence to support direct dissociation of the $\mathrm{CH}_{3} \mathrm{NH}_{2}-\mathrm{CH}$ dative adduct by $\mathrm{H}$-loss to form the $\mathrm{CH}_{3} \mathrm{HN}-\mathrm{CH}$ methyl amino carbene at $\mathrm{m} / \mathrm{z}$ 43 or $\mathrm{CH}_{3}-$ loss to form the $\mathrm{H}_{2} \mathrm{~N}-\mathrm{CH}$ isomer at $\mathrm{m} / \mathrm{z} 29$. The dative intermediate is therefore more likely to isomerize through either $\mathrm{H}$ - or $\mathrm{CH}_{3}$-transfer to give $\mathrm{CH}_{3} \mathrm{HN}-\mathrm{CH}_{2}$ and/or $\mathrm{H}_{2} \mathrm{~N}-$ $\mathrm{CHCH}_{3}$ intermediates. The so-formed $\mathrm{CH}_{3} \mathrm{HN}-\mathrm{CH}_{2}$ isomer can lose either a $\mathrm{H}$ atom or a $\mathrm{CH}_{3}$ group to give the detected $\mathrm{CH}_{3} \mathrm{~N}=\mathrm{CH}_{2}$ and $\mathrm{HN}=\mathrm{CH}_{2}$ final imine products. The $\mathrm{H}_{2} \mathrm{~N}-\mathrm{CHCH}_{3}$ intermediate resulting from the $\mathrm{CH}_{3}$ transfer can lose one of the two $\mathrm{H}$-atoms on the nitrogen to form the cis or trans $\mathrm{HN}=\mathrm{CHCH}_{3}$ imines or the $\mathrm{H}$-atom initially on the carbon atom of the $\mathrm{CH}$ radical to form the $\mathrm{H}_{2} \mathrm{~N}-\mathrm{CCH}_{3}$ amino carbene. Loss of the methyl group on the carbon atom leads to the $\mathrm{H}_{2} \mathrm{~N}-\mathrm{CH}$ amino carbene. We have no evidence of the $\mathrm{H}_{2} \mathrm{~N}-\mathrm{CH}$ and $\mathrm{H}_{2} \mathrm{~N}-$ $\mathrm{CHCH}_{3}$ amino carbene in the reaction flow.

The 0.9:1 branching ratio for $\mathrm{CH}_{3} \mathrm{~N}=\mathrm{CH}_{2}: \mathrm{HN}=\mathrm{CHCH}_{3}$ at $\mathrm{m} / \mathrm{z} 43$ (Figure 5) suggests that the $\mathrm{CH}_{3}$-tranfer may compete with the $\mathrm{H}$-transfer following the formation of the initial dative adduct. In recent literature, methyl-group transfers have not been necessary to explain the observed reaction products from a $\mathrm{CH}$ reaction with saturated or unsaturated hydrocarbons. ${ }^{40}$ In order to gain additional knowledge about the likelihood of the methyl-group transfer, the saddle points for the $\mathrm{H}$ - and $\mathrm{CH}_{3}$-transfers from the $\mathrm{CH}_{3} \mathrm{H}_{2} \mathrm{~N}-\mathrm{CH}$ intermediate have been calculated at the CBS-QB3 level of theory. Figure 11 displays the energetics for the initial reaction adduct, the two isomers resulting from the $\mathrm{H}$ - and $\mathrm{CH}_{3}$-transfer, as well as the corresponding saddle points. All the energies are calculated relatively to that of the reactants. At this level of theory the saddle point for the H-transfer is found to be below that of the reactants while that for the $\mathrm{CH}_{3}$-tranfer is $17.1 \mathrm{~kJ} \cdot \mathrm{mol}^{-1}$ above that of $\mathrm{CH}+\mathrm{CH}_{3} \mathrm{NH}_{2}$. 


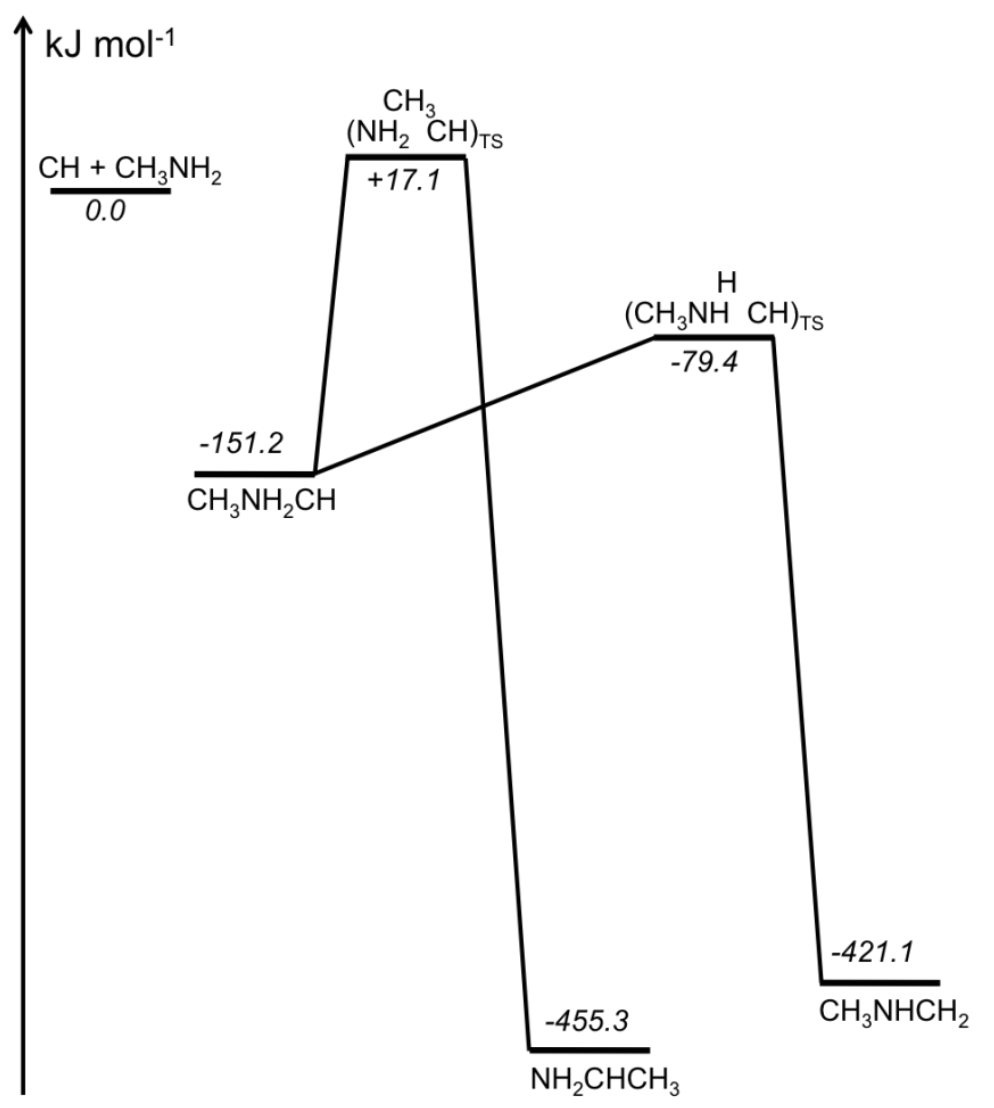

Figure 11. $\mathrm{C}_{2} \mathrm{H}_{6} \mathrm{~N}$ stationary points calculated using the CBS-QB3 method.

Estimates for absolute uncertainty of the CBS-QB3 method ${ }^{68}$ make it unlikely that the CBSQB3 saddle point energy for methyl transfer lies below the reactant energy. Although the CBSQB3 method has been shown not to be appropriate to calculate the energy of a dative interaction, ${ }^{68,69}$ the relative energies of the two saddle points displayed in Figure 11 show that the $\mathrm{CH}_{3}$ transfer is energetically less favorable than the H-transfer. As suggested for $\mathrm{B}-\mathrm{N}$ dative bonds, the MP2 method and higher level methods may be more appropriate for such studies. ${ }^{69}$ The detection of $\mathrm{HN}=\mathrm{CHCH}_{3}$ from the $\mathrm{CH}+\mathrm{CH}_{3} \mathrm{NH}_{2}$ reaction may be explained by a lowering of the $\mathrm{CH}_{3}$-transfer transition state below that of the reactants due to the dative interaction. Alternatively, direct insertion of the $\mathrm{CH}$ radical into the $\mathrm{N}-\mathrm{C}$ or a methyl $\mathrm{C}-\mathrm{H}$ bond could become a competitive entrance channel. Scheme 3 displays a possible mechanism for radical insertion into a $\mathrm{C}-\mathrm{H}$ bond requiring only one $\mathrm{H}$-atom transfer (and no $\mathrm{CH}_{3}$ transfer) to form the $\mathrm{H}_{2} \mathrm{~N}-\mathrm{CHCH}_{3}$ intermediate. Loss of a $\mathrm{H}$-atom from the nitrogen forms the cis- or trans- 
methylimine isomers. It is possible that such a mechanism become more favorable as the number of methyl groups on the reactant amine increases. Further calculations at a higher level of theory are required in order to discriminate between the direct insertion and dative intermediate mechanisms for this reaction.

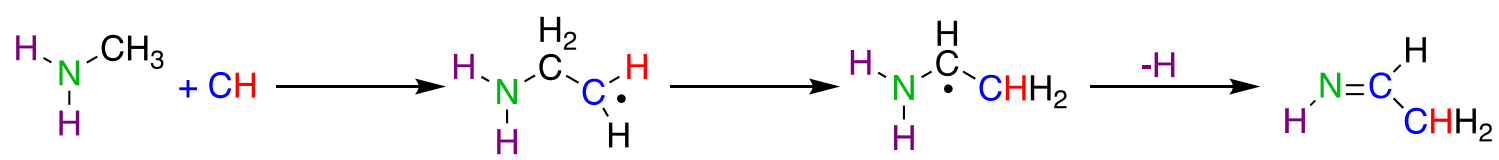

Scheme 3

The $\mathrm{CH}+\left(\mathrm{CH}_{3}\right)_{2} \mathrm{NH}$ reaction may be discussed using a similar dative mechanism as those described for the $\mathrm{CH}+\mathrm{NH}_{3}$ and $\mathrm{CH}+\mathrm{CH}_{3} \mathrm{NH}_{2}$ reactions. As for the reaction of $\mathrm{CH}$ with MA, the product detection study does not allow differentiating between a direct $\mathrm{N}-\mathrm{H} / \mathrm{N}-\mathrm{C}$ insertion and an addition/isomerization entrance channel. The non-detection of the reactive $\left(\mathrm{CH}_{3}\right)_{2} \mathrm{~N}-\mathrm{CH}$ and $\mathrm{CH}_{3} \mathrm{HN}-\mathrm{CH}$ amino carbenes suggests that direct decomposition of the $\left(\mathrm{CH}_{3}\right)_{2} \mathrm{HN}-\mathrm{CH}$ dative adduct through $\mathrm{H}-$ or $\mathrm{CH}_{3}$-loss is not a competitive channel. Scheme 4 shows the proposed mechanism based on the isomerization of a datively bond intermediate to form imine products. Bold arrows correspond to observed channels. Pathways to amino carbene compounds are not shown.

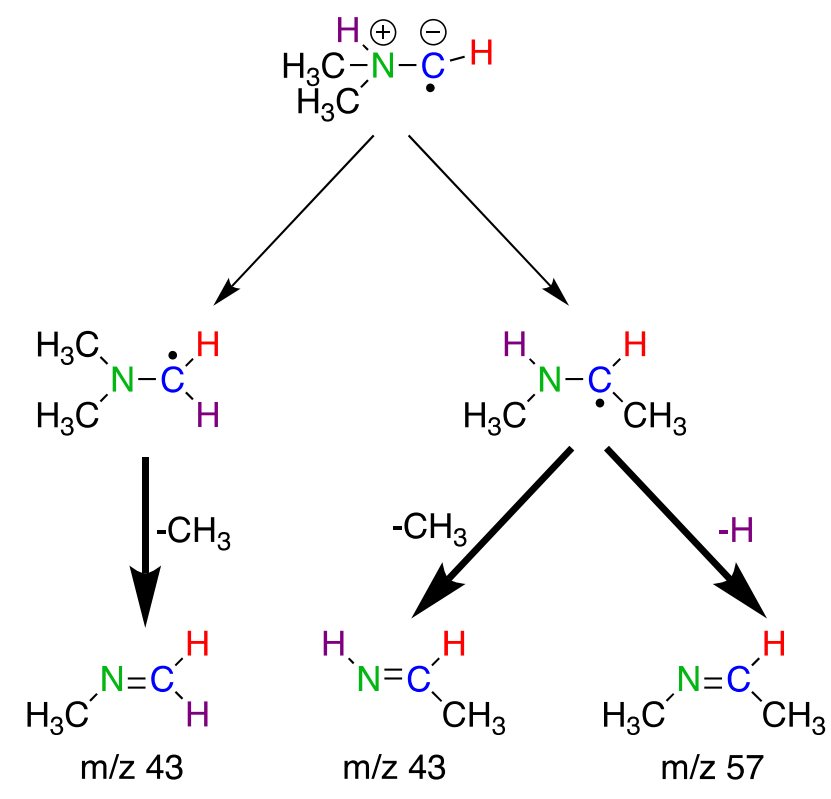




\section{Scheme 4}

The initial $\left(\mathrm{CH}_{3}\right)_{2} \mathrm{HN}-\mathrm{CH}$ dative intermediate may isomerize to $\left(\mathrm{CH}_{3}\right)_{2} \mathrm{~N}-\mathrm{CH}_{2}$ or $\mathrm{CH}_{3} \mathrm{HN}-\mathrm{CHCH}_{3}$ through $\mathrm{H}$ - or $\mathrm{CH}_{3}$-transfers, respectively. The detection of $\mathrm{CH}_{3} \mathrm{~N}=\mathrm{CH}_{2}$ and $\mathrm{HN}=\mathrm{CHCH}_{3}$ may be explained by loss of a methyl group on the nitrogen atom from the $\mathrm{H}$ transfer and the $\mathrm{CH}_{3}$-transfer isomers. Loss of a $\mathrm{H}$ atom from the $\mathrm{CH}_{3} \mathrm{HN}-\mathrm{CHCH}_{3}$ isomer leads to the observed $\mathrm{CH}_{3} \mathrm{~N}=\mathrm{CHCH}_{3}$ product at $\mathrm{m} / \mathrm{z}$ 57. The $\mathrm{CH}_{3} \mathrm{HN}-\mathrm{CHCH}_{3}$ intermediate may also be formed through a more direct $\mathrm{C}-\mathrm{H}$ insertion mechanism as proposed in scheme 3 for the methyl substituted amine. The fit to the photoionization spectrum in Figure 8 suggests the detection of the $\mathrm{HN}=\mathrm{C}\left(\mathrm{CH}_{3}\right)_{2}$ isomer. Its formation through the formation of the dative intermediate would require the transfer of two methyl groups from the nitrogen atom to the carbon atom to give the $\mathrm{HN}-\mathrm{CH}\left(\mathrm{CH}_{3}\right)_{2}$ intermediate or one methyl group through a $\mathrm{C}-\mathrm{H}$ or $\mathrm{N}-\mathrm{C}$ insertion mechanism.

The main observed $\mathrm{H}$ - and $\mathrm{CH}_{3}$-loss products from the $\mathrm{CH}+\left(\mathrm{CH}_{3}\right)_{3} \mathrm{~N}$ reaction are $\mathrm{CH}_{3} \mathrm{~N}=\mathrm{CH}_{2}$ and $\mathrm{HN}=\mathrm{CHCH}_{3}$ at $\mathrm{m} / \mathrm{z} 43$ and $\mathrm{CH}_{3} \mathrm{~N}=\mathrm{C}\left(\mathrm{CH}_{3}\right)_{2}$ at $\mathrm{m} / \mathrm{z}$ 71. Isomers at $\mathrm{m} / \mathrm{z} 57$ are also detected but are a minor pathway with an overall ion signal representing only $10 \%$ of the identified reaction products. Scheme 5 displays the possible reaction pathways following isomerization of the $\left(\mathrm{CH}_{3}\right)_{3} \mathrm{~N}-\mathrm{CH}$ dative adduct by methyl transfer or isomerization of the $\mathrm{C}-$ $\mathrm{H}$ insertion adduct by $\mathrm{H}$-transfer. Bold arrows correspond to observed channels. The minor dimethylimine channel detected at $\mathrm{m} / \mathrm{z} 57$ may be formed by methyl loss from the $\left(\mathrm{CH}_{3}\right)_{2} \mathrm{~N}-$ $\mathrm{CHCH}_{3}$ intermediate to give $\mathrm{CH}_{3} \mathrm{~N}-\mathrm{CHCH}_{3}$. Formation of $\mathrm{HN}=\mathrm{C}\left(\mathrm{CH}_{3}\right)_{2}$ would require a methyl group transfer and a H-transfer, which is unlikely. 


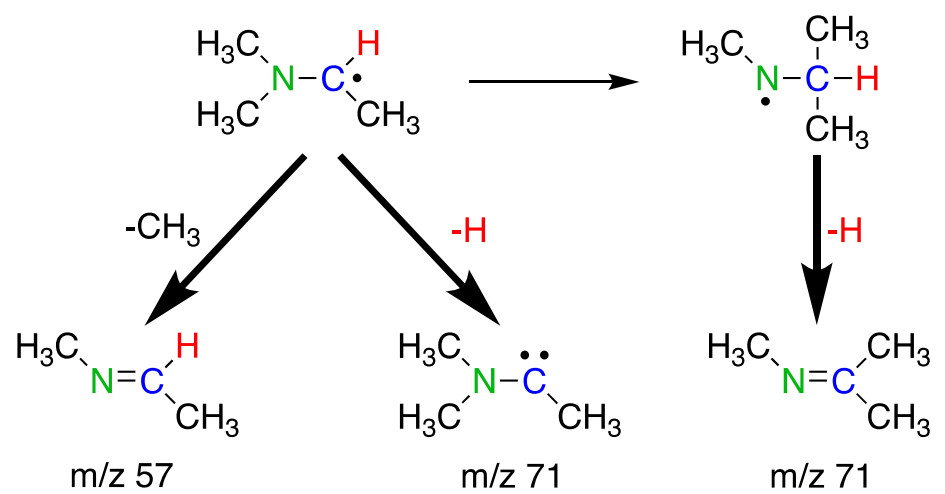

Scheme 5

In scheme 5, formation of the $\mathrm{CH}_{3} \mathrm{~N}=\mathrm{C}\left(\mathrm{CH}_{3}\right)_{2}$ isomer at $\mathrm{m} / \mathrm{z} 71$ requires the transfer of a $\mathrm{CH}_{3}$ group from the $\left(\mathrm{CH}_{3}\right)_{2} \mathrm{~N}-\mathrm{CHCH}_{3}$ intermediate to form a $\mathrm{CH}_{3} \mathrm{~N}-\mathrm{CH}\left(\mathrm{CH}_{3}\right)_{2}$ intermediate followed by $\mathrm{H}$-loss. This mechanism is similar to the successive two-H-atom transfers predicted by Blitz et al. ${ }^{15}$ for the $\mathrm{CH}+\mathrm{NH}_{3}$ reaction. High-level quantum calculations and RRKM-based master equation calculations would be useful to explore these mechanisms in more detail. Formation of methylimine products by the $\mathrm{CH}+\mathrm{TMA}$ reaction requires the loss of an ethyl group. Although we do detect methylimines at $\mathrm{m} / \mathrm{z}=43$ in this reaction, the absence of signal from the expected co-product $\mathrm{C}_{2} \mathrm{H}_{5}$ radical $(\mathrm{IE}=8.12 \mathrm{eV})^{65}$ in Figure 9 is puzzling.

\subsection{Relevance for combustion chemistry}

Prediction of NOx formation from combustion processes is a very active subject of research, especially due to the increasing use of fuels derived from biogenic sources (e.g., biomass, agricultural wastes). ${ }^{70-74}$ Biomass combustion could contribute to nitrogen conversion through the formation of nitrogenized intermediates such as $\mathrm{HCN}$. Their formation may depend on the fuel structure. Accordingly, several studies have focused on flames burning nitrogenized compounds (e.g., ammonia, pyrrole, pyridine). ${ }^{75-80}$ The spatial detection of nitrogen containing radicals in laminar flames of DMA, ethylamine, ${ }^{81}$ and morpholine ${ }^{82}$ suggests that the $\mathrm{NH}_{2}$ radical is formed very early in the combustion process and further reacts to form $\mathrm{HCN}, \mathrm{CN}$, and NO. The mole fraction of ammonia is also found to be relatively large $\left(6 \times 10^{-2}\right)$ and is likely 
to play a role in the formation of nitrogen reactive species and nitrogen containing hydrocarbons. The reactions of ammonia with other abundant combustion radicals is therefore likely to affect the formation of $\mathrm{NH}_{2}$ radicals and ultimately $\mathrm{NO}$. In the present study, the abstraction channel $\mathrm{NH}_{2}+\mathrm{CH}_{2}$ from the $\mathrm{CH}+\mathrm{NH}_{3}$ reaction is not detected at the temperature of the flow $(373 \mathrm{~K})$. This product channel is calculated to be endothermic by $20.9 \mathrm{~kJ} \mathrm{~mol}^{-1}$ $(\mathrm{CCSD}(\mathrm{T}))^{15}$ and could become accessible at flame temperatures $(>2000 \mathrm{~K})$. The formation of the thermodynamically favorable $\mathrm{HN}=\mathrm{CH}_{2}$ may still remain a dominant pathway. Further reaction of the detected imine may lead to larger nitrogen containing molecules and contribute to incorporating nitrogen in large hydrocarbons such as polycyclic nitrogen containing aromatic hydrocarbons.

Imine and methyl substituted imines have been detected during the combustion of biomass model fuels. ${ }^{82}$ As for ammonia, the reaction of methyl substituted amines with the $\mathrm{CH}$ radical may contribute to their formation and to the overall molecular growth scheme in combustion. Abstraction of a $\mathrm{H}$-atom from the carbon group substituent may become more likely as the number of $\mathrm{C}-\mathrm{H}$ bonds increase. The product detection preformed in the present study together with the temperature independent rate coefficient reported by Zabarnick et al. ${ }^{14}$ suggest that the addition-elimination mechanism will still play a role even at combustionrelevant temperatures. The isomer resolved detection of the methyl substituted imines and their proposed formation mechanisms is likely to improve the quality of the chemical models used to reproduce their spatial molar fraction in flames. ${ }^{82}$

\section{CONCLUSION}

The systematic study of the reaction of the methylidyne radical with ammonia, methyl, dimethyl, and trimethyl amine provides empirical evidence supporting a general reaction mechanism for $\mathrm{CH}$ reacting with amines. The detection of mainly the imine isomer upon reaction of $\mathrm{CH}$ with ammonia is in agreement with the mechanism proposed by Blitz et al. ${ }^{15}$ 
based on high-level calculations and RRKM-based master equation calculations. According to this mechanism, the insertion of the $\mathrm{CH}$ radical onto a $\mathrm{N}-\mathrm{H}$ bond proceeds by the initial formation of a dative $\mathrm{C}-\mathrm{N}$ bond. The donor-acceptor type mechanism is barrierless and is likely to occur over a wide range of temperatures, including under combustion conditions.

Although no theoretical data are available for the $\mathrm{CH}$ reaction with methyl substituted amines, a similar mechanism as that proposed for the reaction with ammonia may be employed to interpret the products detected for the $\mathrm{CH}+\mathrm{MA}$, DMA, and TMA. For each reaction, the detection of $\mathrm{H}$ - and $\mathrm{CH}_{3}$-loss products may be explained in part through isomerization of an initial dative adduct formed by the sharing of the nitrogen lone pair with the carbon atom of the $\mathrm{CH}$ radical. Kinetic traces of the reaction products show no evidence of the formation of the reactive methyl-substituted amino carbene isomers. The detection of the methylimine with the methyl group on the carbon atom in the case of the $\mathrm{CH}+\mathrm{MA}$ reaction suggests that the transfer of a methyl group could be a competitive pathway, but our calculations show a barrier well above reactant energy for this process. However, a direct insertion pathway of the $\mathrm{CH}$ radical into a methyl $\mathrm{C}-\mathrm{H}$ bond may become competitive as the number of methyl group increases. Our data do not allow differentiating between a dative mechanism and direct insertion, but provide evidence that the latter should be considered. In the case of the $\mathrm{CH}+$ TMA reaction, direct insertion of the $\mathrm{CH}$ radical into a $\mathrm{C}-\mathrm{H}$ bond would lead to a pathway involving only one $\mathrm{CH}_{3}$-transfer followed by $\mathrm{H}$-loss to explain the formation of the detected $\mathrm{CH}_{3} \mathrm{~N}=\mathrm{C}\left(\mathrm{CH}_{3}\right)_{2}$ isomer. Methylimine isomers are detected from both the $\mathrm{CH}+\mathrm{DMA}$ and $\mathrm{CH}$ + TMA reactions. The lack of imine absolute ionization cross section does not allow to quantify their branching fractions. In the case of the $\mathrm{CH}+\mathrm{TMA}$ reaction formation of methylimines should also produce a $\mathrm{C}_{2} \mathrm{H}_{5}$ radical, which we do not observe.

Overall the dative reaction mechanism proposed by Blitz et al. ${ }^{15}$ for the $\mathrm{CH}+\mathrm{NH}_{3}$ reaction as well as Ramasami et al. ${ }^{67}$ for the $\mathrm{CH}_{2} / \mathrm{CHCl} / \mathrm{CHF}+\mathrm{CH}_{3} \mathrm{NH}_{2}$ is not sufficient to 
explain all the detected products and a $\mathrm{C}-\mathrm{H}$ insertion mechanism is likely to become favorable for alklyl substituted amines. Although the present studies provide valuable data for the understanding of the reactivity of amines with the $\mathrm{CH}$ radical, further theoretical studies including RRKM-based master equations on the potential energy surface and experimental studies of photoionization cross sections are paramount toward the full understanding of the reaction mechanism, especially about the competition between direct $\mathrm{N}-\mathrm{C}$ insertion and formation of an initial dative intermediate.

\section{ACKNOWLEDGEMENTS}

The Rennes team acknowledges support from the Agence Nationale de la Recherche, contract ANR-11-BS04-024- CRESUSOL-01, the French INSU/CNRS Program "Physique et Chimie du Milieu Interstellaire'” (PCMI), the Institut Nationalde Physique (INPCNRS), the Région Bretagne and the Université de Rennes 1. S.D.L.P. acknowledges financial support from the Institut Universitaire de France. FG and KLC acknowledge travel support from the Eberly College of Art and Sciences and The Bennett Department of Chemistry at West Virginia University as well as the WVU Research Corporation PSCoR program. We thank Messrs. Howard Johnsen and Raybel Almeida for technical support of this experiment. D.L.O. and the instrumentation for this work are supported by the Division of Chemical Sciences, Geosciences, and Biosciences, the Office of Basic Energy Sciences, the U.S. Department of Energy. Sandia National Laboratories is a multimission laboratory managed and operated by National Technology and Engineering Solutions of Sandia, LLC., a wholly owned subsidiary of Honeywell International, Inc. for the U.S. DOE's National Nuclear Security Administration under contract DE-NA0003525. This paper describes objective technical results and analysis. Any subjective views or opinions that might be expressed in the paper do not necessarily represent the views of the USDOE or the United States Government. This research used resources of the Advanced Light Source, a DOE Office of Science User Facility, which is 
supported by the Direct, Office of Science, Office of Basic Energy Sciences, the U.S. Department of Energy under contract DE-AC02-05CH11231 at Lawrence Berkeley National Laboratory.

Supporting Information: Normalized integrated Franck-Condon factors and photoelectron spectra of the imines and amino carbene isomers. 


\section{References}

(1) Ge, X.; Wexler, A. S.; Clegg, S. L. Atmospheric amines-Part II. Thermodynamic properties and gas/particle partitioning. Atmos.Environ. 2011, 45, 561-577.

(2) Ge, X.; Wexler, A. S.; Clegg, S. L. Atmospheric amines-Part I. A review. Atmos. Environ. 2011, 45, 524-546.

(3) Cullis, C. F.; Khokhar, B. A. The inhibiting influence of aliphatic amines on the explosive oxidation of acethayldehyde. Trans. Faradav Societv 1960, 56, 1235-1244.

(4) Shi, J. C.; Shang, Y. L.; Ye, W.; Zhang, R. T.; Luo, S. N. Shock-tube experiments and chemical kinetic modeling study of $\mathrm{CH}_{4}$ sensitized by $\mathrm{CH}_{3} \mathrm{NHCH}_{3}$. Energy \& Fuels 2018, 32, $5588-5595$.

(5) Moore, F.; Tipper, C. F. H. The effect of additives on low-temperature hydrocarbon ignition in a flow system. Combust. Flame 1972, 19, 81-87.

(6) Lucassen, A.; Zhang, K.; Warkentin, J.; Moshammer, K.; Glarborg, P.; Marshall, P.; Kohse-Höinghaus, K. Fuel-nitrogen conversion in the combustion of small amines using dimethylamine and ethylamine as biomass-related model fuels. Combust. Flame 2012, 159, 2254-2279.

(7) Tipper, C. F. H.; Titchard, A. The effect of additives on the cool flame combustion of nheptane. Combust. Flame 1971, 16, 223-232.

(8) Jones, P. W.; Selby, K.; Tidball, M. J.; Waddington, D. J. Inhibition of gas-phase oxidation reactions by aliphatic amines and related compounds. Combust. Flame 1974, 22, 209-217.

(9) Atkinson, R.; Pitts Jr, J. N. Kinetics of the reactions of $\mathrm{O}\left({ }^{3} \mathrm{P}\right)$ atoms with the amines $\mathrm{CH}_{3} \mathrm{NH}_{2}, \mathrm{C}_{2} \mathrm{H}_{5} \mathrm{NH}_{2},\left(\mathrm{CH}_{3}\right)_{2} \mathrm{NH}$, and $\left(\mathrm{CH}_{3}\right)_{3} \mathrm{~N}$ over the temperature range $298-440 \mathrm{~K} . J$. Chem. Phys. 1978, 68, 911-915. 
(10) Slagle, I. R.; Dudich, J. F.; Gutman, D. Direct identification of reactive routes in the reaction of oxygen atoms with dimethylamine. Chem. Phvs. Lett. 1979, 61, 620-624.

(11) Atkinson, R.; Baulch, D. L.; Cox, R. A.; Crowley, J. N.; Hampson, R. F.; Hynes, R. G.; Jenkin, M. E.; Rossi, M. J.; Troe, J. Evaluated kinetic and photochemical data for atmospheric chemistry: Volume I - gas phase reactions of $\mathrm{O}_{\mathrm{x}}, \mathrm{HO}_{\mathrm{x}}, \mathrm{NO}_{\mathrm{x}}$ and $\mathrm{SO}_{\mathrm{x}}$ species. Atmos. Chem. Phvs. 2004, 4, 1461-1738.

(12) Sims, I. R.; Queffelec, J. L.; Defrance, A.; Rebrionrowe, C.; Travers, D.; Bocherel, P.; Rowe, B. R.; Smith, I. W. M. Ultralow temperature kinetics of neutral-neutral reactions - The technique and results for the reactions $\mathrm{CN}+\mathrm{O}_{2}$ down to $13 \mathrm{~K}$ and $\mathrm{CN}+\mathrm{NH}_{3}$ down to $25 \mathrm{~K} . J$. Chem. Phys. 1994, 100, 4229-4241.

(13) Nizamov, B.; Leone, S. R. Rate Coefficients and Kinetic Isotope Effect for the $\mathrm{C}_{2} \mathrm{H}$ Reactions with $\mathrm{NH}_{3}$ and $\mathrm{ND}_{3}$ in the 104- $294 \mathrm{~K}$ Temperature Range. J. Phys. Chem. A 2004, 108, 3766-3771.

(14) Zabarnick, S.; Fleming, J. W.; Lin, M. C. Kinetics of the methylidyne (CHX²PI) radical reactions with ammonia and methylamines. Chem. Phvs. 1989, 132, 407-411.

(15) Blitz, M. A.; Talbi, D.; Seakins, P. W.; Smith, I. W. M. Rate constants and branching ratios for the reaction of $\mathrm{CH}$ radicals with $\mathrm{NH}_{3}$ : A combined experimental and theoretical study. J.Phvs. Chem. A 2012, 116, 5877-5885.

(16) Corchado, J. C.; Espinosa-Garcia, J.; Hu, W.-P.; Rossi, I.; Truhlar, D. G. Dual-level reaction-path dynamics (the approach to VTST with semiclassical tunneling). Application to $\mathrm{OH}+\mathrm{NH}_{3}$. fwdarw. $\mathrm{H}_{2} \mathrm{O}+\mathrm{NH}_{2}$. L. Phvs. Chem. 1995, 99, 687-694.

(17) Meads, R. F.; Maclagan, R. G.; Phillips, L. F. Kinetics, energetics, and dynamics of the reactions of cyanogen with ammonia and ammonia-d3. J.Phvs. Chem. 1993, 97, 3257-3265. 
(18) Tian, W.; Wang, W.; Zhang, Y.; Wang, W. Direct dynamics study on the mechanism and the kinetics of the reaction of $\mathrm{CH}_{3} \mathrm{NH}_{2}$ with $\mathrm{OH}$. Int.J. Ouantum Chem 2009, 109, 15661575.

(19) Onel, L.; Blitz, M. A.; Breen, J.; Rickardcd, A. R.; Seakins, P. W. Branching ratios for the reactions of $\mathrm{OH}$ with ethanol amines used in carbon capture and the potential impact on carcinogen formation in the emission plume from a carbon capture plant. Phys. Chem. Chem. Phys. 2015, 17, 25342-25353.

(20) Onel, L.; Blitz, M.; Dryden, M.; Thonger, L.; Seakins, P. Branching ratios in reactions of $\mathrm{OH}$ radicals with methylamine, dimethylamine, and ethylamine. Environ. Sci. Technol. 2014, 48, 9935-9942.

(21) Onel, L.; Thonger, L.; Blitz, M. A.; Seakins, P. W.; Bunkan, A. J. C.; Solimannejad, M.; Nielsen, C. J. Gas-phase reactions of $\mathrm{OH}$ with methyl amines in the presence or absence of molecular oxygen. An experimental and theoretical study. J. Phys. Chem. A 2013, 117, 10736-10745.

(22) Onel, L.; Blitz, M. A.; Seakins, P. W. Direct determination of the rate coefficient for the reaction of $\mathrm{OH}$ radicals with monoethanol amine (MEA) from 296 to 510 K. J. Phys. Chem. Lett. 2012, 3, 853-856.

(23) Love, N.; Parthasarathy, R. N.; Gollahalli, S. R. Concentration measurements of CH and $\mathrm{OH}$ radicals in laminar biofuel flames. Int. J. Green Energy 2011, 8, 113-120.

(24) Tinaut, F. V.; Reyes, M.; Giménez, B.; Pastor, J. V. Measurements of $\mathrm{OH}^{*}$ and $\mathrm{CH}^{*}$ chemiluminescence in premixed flames in a constant volume combustion bomb under autoignition conditions. Energy \& Fuels 2010, 25, 119-129.

(25) Glarborg, P.; Miller, J. A.; Ruscic, B.; Klippenstein, S. J. Modeling nitrogen chemistry in combustion. Prog. Enerov Combust. Sci. 2018, 67, 31-68. 
(26) Vereecken, L.; Pierloot, K.; Peeters, J. B3LYP-DFT characterization of the potential energy surface of the $\mathrm{CH}\left(\mathrm{X}^{2} \Pi\right)+\mathrm{C}_{2} \mathrm{H}_{2}$ reaction. L.Chem. Phys. 1998, 108, 1068-1080.

(27) Vereecken, L.; Peeters, J. Detailed microvariational RRKM master equation analysis of the product distribution of the $\mathrm{C}_{2} \mathrm{H}_{2}+\mathrm{CH}\left(\mathrm{X}^{2} \Pi\right)$ reaction over extended temperature and pressure ranges. L.Phvs. Chem.A 1999, 103, 5523-5533.

(28) Goulay, F.; Trevitt, A. J.; Meloni, G.; Selby, T. M.; Osborn, D. L.; Taatjes, C. A.; Vereecken, L.; Leone, S. R. Cyclic versus linear isomers produced by reaction of the methylidyne radical $(\mathrm{CH})$ with small unsaturated hydrocarbons. J. Am. Chem. Soc. 2009, 131, 993-1005.

(29) Fenimore, C. P. Formation of nitric oxide in premixed hydrocarbon flames. Proc. Comb. Instit. 1971, 13, 373-380.

(30) Miller, J. A.; Bowman, C. T. Mechanism and modeling of nitrogen chemistry in combustion. Prog. Energy Combust. Sci. 1989, 15, 287-338.

(31) Becker, K. H.; Engelhardt, B.; Geiger, H.; Kurtenbach, R.; Schrey, G.; Wiesen, P. Temperature dependence of the $\mathrm{CH}+\mathrm{N}_{2}$ reaction at low total pressure. Chem. Phys. Lett. 1992, 195, 322-328.

(32) Becker, K. H.; Engelhardt, B.; Geiger, H.; Kurtenbach, R.; Weisen, P. Temperature dependence of the reactions of $\mathrm{CH}$ radicals with $\mathrm{NO}, \mathrm{NH}_{3}$ and $\mathrm{N}_{2} \mathrm{O}$ in the range $200-1300 \mathrm{~K}$. Chem. Phvs. Lett. 1993, 210, 135-140.

(33) Becker, K. H.; Engelhardt, B.; Geiger, H.; Kurtenbach, R.; Wiesen, P. Temperature dependence of the reactions of $\mathrm{CH}$ radicals with $\mathrm{NO}, \mathrm{NH}_{3}$ and $\mathrm{N}_{2} \mathrm{O}$ in the range 200-1300-K. Chem. Phvs.Lett. 1993, 210, 135-140.

(34) Geiger, H.; Wiesen, P.; Becker, K. H. A product study of the reaction of CH radicals with nitric oxide at $298 \mathrm{~K}$. Phvs. Chem. Chem. Phvs. 1999, 1, 5601-5606. 
(35) Cui, Q.; Morokuma, K.; Bowman, J. M.; Klippenstein, S. J. The spin-forbidden reaction $\mathrm{CH}\left({ }^{2} \mathrm{\Pi}\right)+\mathrm{N}_{2} \rightarrow \mathrm{HCN}+\mathrm{N}\left({ }^{4} \mathrm{~S}\right)$ revisited. II. Nonadiabatic transition state theory and application. L.Chem. Phvs. 1999, 110, 9469-9482.

(36) Moskaleva, L. V.; Lin, M. C. The spin-conserved reaction $\mathrm{CH}+\mathrm{N}_{2} \rightarrow \mathrm{H}+\mathrm{NCN}$ : A major pathway to prompt NO studied by quantum/statistical theory calculations and kinetic modeling of rate constant. Proc. Comb.Instit. 2000, 28, 2393-2401.

(37) Berman, M. R.; Tsuchiya, T.; Gregušová, A.; Perera, S. A.; Bartlett, R. J. HNNC radical and its role in the $\mathrm{CH}+\mathrm{N} 2$ reaction. $\mathrm{J}$. Phvs. Chem.A 2007, 111, 6894-6899.

(38) Goos, E.; Sickfeld, C.; Mauß, F.; Seidel, L.; Ruscic, B.; Burcat, A.; Zeuch, T. Prompt NO formation in flames: The influence of NCN thermochemistry. Proc. Comb. Instit. 2013, $34,657-666$.

(39) Bocherel, P.; Herbert, L. B.; Rowe, B. R.; Sims, I. R.; Smith, I. W.; Travers, D. Ultralow-temperature kinetics of $\mathrm{CH}\left(\mathrm{X}^{2} \Pi\right)$ reactions: Rate coefficients for reactions with $\mathrm{O}_{2}$ and NO $(\mathrm{T}=13-708 \mathrm{~K})$, and with $\mathrm{NH}_{3}(\mathrm{~T}=23-295 \mathrm{~K})$. L.Phvs.Chem. 1996, 100, 30633069.

(40) Trevitt, A. J.; Goulay, F. Insights into gas-phase reaction mechanisms of small carbon radicals using isomer-resolved product detection. Phvs. Chem. Chem. Phvs. 2016, 18, 58675882.

(41) Osborn, D. L.; Zou, P.; Johnsen, H.; Hayden, C. C.; Taatjes, C. A.; Knyazev, V. D.; North, S. W.; Peterka, D. S.; Ahmed, M.; Leone, S. R. The multiplexed chemical kinetic photoionization mass spectrometer: A new approach to isomer-resolved chemical kinetics. Rev. Sci. Instrum. 2008, 79, 104103: 1-10.

(42) Taatjes, C. A.; Hansen, N.; Osborn, D. L.; Kohse-Höinghaus, K.; Cool, T. A.; Westmoreland, P. R. “Imaging” combustion chemistry via multiplexed synchrotronphotoionization mass spectrometry. Phvs. Chem. Chem. Phvs. 2008, 10, 20-34. 
(43) Goulay, F.; Trevitt, A. J.; Savee, J. D.; Bouwman, J.; Osborn, D. L.; Taatjes, C. A.; Wilson, K. R.; Leone, S. R. Product detection of the $\mathrm{CH}$ radical reaction with acetaldehyde. L.Phys. Chem.A 2012, 116, 6091-6106.

(44) Zou, P.; Shu, J.; Sears, T. J.; Hall, G. E.; North, S. W. Photodissociation of bromoform at $248 \mathrm{~nm}$ : Single and multiphoton processes. J.Phvs.Chem.A 2004, 108, 1482-1488.

(45) Romanzin, C.; Boye-Peronne, S.; Gauyacq, D.; Benilan, Y.; Gazeau, M. C.; Douin, S. $\mathrm{CH}$ radical production from $248 \mathrm{~nm}$ photolysis or discharge-jet dissociation of $\mathrm{CHBr} 3$ probed by cavity ring-down absorption spectroscopy. J. Chem. Phys. 2006, 125, 114312: 1-9. (46) Bourgalais, J.; Spencer, M.; Osborn, D. L.; Goulay, F.; Le Picard, S. D. Reactions of atomic carbon with butene isomers: Implications for molecular growth in carbon-rich environments. L.Phvs. Chem.A 2016, 120, 9138-9150.

(47) Capron, M.; Bourgalais, J.; Kailasanathan, R. K. A.; Osborn, D. L.; Le Picard, S. D.; Goulay, F. Flow tube studies of the $\mathrm{C}\left({ }^{3} \mathrm{P}\right)$ reactions with ethylene and propylene. Phys. Chem. Chem. Phvs. 2015, 17, 23833-23846.

(48) Montgomery, J. A.; Frisch, M. J.; Ochterski, J. W.; Petersson, G. A. A complete basis set model chemistry. VI. Use of density functional geometries and frequencies. J. Chem. Phys. 1999, 110, 2822-2827.

(49) Montgomery, J. A.; Frisch, M. J.; Ochterski, J. W.; Petersson, G. A. A complete basis set model chemistry. VII. Use of the minimum population localization method. J. Chem. Phys. 2000, 112, 6532-6542.

(50) Barone, V.; Bloino, J.; Biczysko, M.; Santoro, F. Fully integrated approach to compute vibrationally resolved optical spectra: from small molecules to macrosystems. J. Chem. Theo. Comput. 2009, 5, 540-554. 
(51) Goulay, F.; Rebrion-Rowe, C.; Biennier, L.; Le Picard, S. D.; Canosa, A.; Rowe, B. R. Reaction of anthracene with $\mathrm{CH}$ radicals: An experimental study of the kinetics between 58 and 470 K. L.Phvs. Chem.A 2006, 110, 3132-3137.

(52) Herbert, L. B.; Sims, I. R.; Smith, I. W. M.; Stewart, D. W. A.; Symonds, A.; Canosa, A.; Rowe, B. R. Rate constants for the relaxation of $\mathrm{CH}(\mathrm{X}(2) \mathrm{pi}, \mathrm{nu}=1)$ by $\mathrm{CO}$ and $\mathrm{N}-2$ at temperatures from 23 to 584 K. L.Phvs. Chem. 1996, 100, 14928-14935.

(53) Brownsword, R. A.; Herbert, L. B.; Smith, I. W. M.; Stewart, D. W. A. Pressure and temperature dependence of the rate constants for the association reactions of $\mathrm{CH}$ radicals with CO and N-2 between 202 and 584 K. L.Chem.Soc. Faradav 1996, 92, 1087-1094.

(54) Ruzsicska, B. P.; Jodhan, A.; Choi, H. K. J.; Strausz, O. P.; Bell, T. N. Chemistry of carbynes: reaction of CF, CCl, and CBr with alkenes. L.Am.Chem.Soc. 1983, 105, 24892490.

(55) James, F. C.; Ruzsicska, B.; McDaniel, R. S.; Dickson, R.; Strausz, O. P.; Bell, T. N. Rate constants for the reaction of the bromomethyne radical with alkynes. Chem. Phys. Lett. 1977, 45, 449-453.

(56) McDaniel, R. S.; Dickson, R.; James, F. C.; Strausz, O. P.; Bell, T. N. Rate parameters for the reactions of the bromomethyne radical. Chem. Phys.Lett. 1976, 43, 130-134.

(57) Daugey, N.; Caubet, P.; Retail, B.; Costes, M.; Bergeat, A.; Dorthe, G. Kinetic measurements on methylidyne radical reactions with several hydrocarbons at low temperatures. Phvs. Chem. Chem. Phvs. 2005, 7, 2921-2927.

(58) Canosa, A.; Sims, I. R.; Travers, D.; Smith, I. W. M.; Rowe, B. R. Reactions of the methylidine radical with $\mathrm{CH}_{4}, \mathrm{C}_{2} \mathrm{H}_{2}, \mathrm{C}_{2} \mathrm{H}_{4}, \mathrm{C}_{2} \mathrm{H}_{6}$, and but-1-ene studied between 23 and $295 \mathrm{~K}$ with a CRESU apparatus. Astron. Astrophvs. 1997, 323, 644-651. 
(59) Goulay, F.; Derakhshan, A.; Maher, E.; Trevitt, A. J.; Savee, J. D.; Scheer, A. M.;

Osborn, D. L.; Taatjes, C. A. Formation of dimethylketene and methacrolein by reaction of the $\mathrm{CH}$ radical with acetone. Phvs. Chem.Chem. Phvs. 2013, 15, 4049-58.

(60) Cheng, B.-M.; Lu, H.-C.; Chen, H.-K.; Bahou, M.; Lee, Y.-P.; Mebel, A. M.; Lee, L. C.; Liang, M.-C.; Yung, Y. L. Absorption cross sections of $\mathrm{NH}_{3}, \mathrm{NH}_{2} \mathrm{D}, \mathrm{NHD}_{2}$, and $\mathrm{ND}_{3}$ in the spectral range $140-220 \mathrm{~nm}$ and implications for planetary isotopic fractionation. Astrophvs. J. 2006, 647, 1535-1542.

(61) Hubin-Franskin, M.-J.; Delwiche, J.; Giuliani, A.; Ska, M.-P.; Motte-Tollet, F.; Walker, I. C.; Mason, N. J.; Gingell, J. M.; Jones, N. C. Electronic excitation and optical cross sections of methylamine and ethylamine in the UV-VUV spectral region. J. Chem. Phys. 2002, 116, 9261-9268.

(62) Halpern, A. M.; Ondrechen, M. J.; Ziegler, L. D. Analysis of the absoprtion and fluorescence spectra of trimethylamine - Determination of the A-X origin and the groundstate inversion barrier. J.Am.Chem.Soc. 1986, 108, 3907-3912.

(63) Bock, H.; Dammel, R. Methanimines RR'C=NR" - Preparation and photoelectron spectra. Chemische Berichte-Recueil 1987, 120, 1961-1970.

(64) Bobeldijk, M.; van der Zande, W. J.; Kistemaker, P. G. Simple models for the calculation of photoionization and electron impact ionization cross section of polyatomic molecules. Chem. Phvs. 1994, 179, 125-130.

(65) NIST, 2005, Standard Reference Database Number 69, NIST Chemistry WebBook, National Institute of Standards and Technology, Gaithersburg MD, 20899 (http://webbook.nist.gov).

(66) Savee, J. D.; Welz, O.; Taatjes, C. A.; Osborn, D. L. New mechanistic insights to the $\mathrm{O}\left({ }^{3} \mathrm{P}\right)+$ propene reaction from multiplexed photoionization mass spectrometry. Phys. Chem. Chem. Phys. 2012, 14, 10410-10423. 
(67) Ramasami, K.; Ramalingam, M.; Venuvanalingam, P. Singlet methylene and halocarbenes insertions into polar N-H bonds of amines J. Theo. Comput. Chem. 2009, 8, 1143-1153.

(68) Simmie, J. M.; Somers, K. P. Benchmarking compound methods (CBS-QB3, CBSAPNO, G3, G4, W1BD) against the active thermochemical tables: A Litmus test for costeffective molecular formation enthalpies. L.Phvs. Chem.A 2015, 119, 7235-7246.

(69) Gilbert, T. M. Tests of the MP2 model and various DFT models in predicting the structures and B-N bond dissociation energies of amine-boranes (X3C)(m)H3-mB$\mathrm{H}(\mathrm{CH} 3)(\mathrm{n}) \mathrm{H} 3-\mathrm{n}(\mathrm{X}=\mathrm{H}, \mathrm{F} ; \mathrm{m}=0-3 ; \mathrm{n}=0-3)$ : Poor preformance of the B3LYP approach for dative B-N bonds. L.Phvs. Chem.A 2004, 108, 2550-2554.

(70) Demirbas, A. Potential applications of renewable energy sources, biomass combustion problems in boiler power systems and combustion related environmental issues. Prog. Energv Combust. Sci. 2005, 31, 171-192.

(71) Kohse-Höinghaus, K.; Oßwald, P.; Cool, T. A.; Kasper, T.; Hansen, N.; Qi, F.; Westbrook, C. K.; Westmoreland, P. R. Biofuel combustion chemistry: From ethanol to biodiesel. Angew. Chem.Int.Ed. 2010, 49, 3572-3597.

(72) Zhang, Y.; Zhang, J.; Sheng, C.; Liu, Y.; Zhao, L.; Ding, Q. Quantitative analysis of $\mathrm{NO}_{x}$ reduction in Oxy-coal combustion. Energv \& Fuels 2011, 25, 1146-1152.

(73) Mendiara, T.; Glarborg, P. Ammonia chemistry in oxy-fuel combustion of methane. Combust. Flame 2009, 156, 1937-1949.

(74) Darvell, L. I.; Jones, J. M.; Gudka, B.; Baxter, X. C.; Saddawi, A.; Williams, A.; Malmgren, A. Combustion properties of some power station biomass fuels. Fuel 2010, 89, 2881-2890. 
(75) Tian, Z.; Li, Y.; Zhang, L.; Glarborg, P.; Qi, F. An experimental and kinetic modeling study of premixed $\mathrm{NH}_{3} / \mathrm{CH}_{4} / \mathrm{O}_{2} /$ Ar flames at low pressure. Combust. Flame 2009, 156, 1413 1426.

(76) Tian, Z.; Li, Y.; Zhang, T.; Zhu, A.; Cui, Z.; Qi, F. An experimental study of lowpressure premixed pyrrole/oxygen/argon flames with tunable synchrotron photoionization. Combust. Flame 2007, 151, 347-365.

(77) Tian, Z.; Li, Y.; Zhang, T.; Zhu, A.; Qi, F. Identification of combustion intermediates in low-pressure premixed pyridine/oxygen/argon flames. L Phvs. Chem.A 2008, 112, 1354913555.

(78) Wang, Z.; Lucassen, A.; Zhang, L.; Yang, J.; Kohse-Höinghaus, K.; Qi, F. Experimental and theoretical studies on decomposition of pyrrolidine. Proc. Comb. Instit. 2011, 33, 415-423.

(79) Duynslaegher, C.; Jeanmart, H.; Vandooren, J. Flame structure studies of premixed ammonia/hydrogen/oxygen/argon flames: Experimental and numerical investigation. Proc. Comb.Instit. 2009, 32, 1277-1284.

(80) Zhang, K.; Li, Y.; Yuan, T.; Cai, J.; Glarborg, P.; Qi, F. An experimental and kinetic modeling study of premixed nitromethane flames at low pressure. Proc. Comb. Instit. 2011, $33,407-414$.

(81) Nau, P.; Seipel, A.; Lucassen, A.; Brockhinke, A.; Kohse-Höinghaus, K. Intermediate species detection in a morpholine flame: contributions to fuel-bound nitrogen conversion from a model biofuel. Exp. Fluids 2010, 49, 761-773.

(82) Lucassen, A.; Labbe, N.; Westmoreland, P. R.; Kohse-Hoinghaus, K. Combustion chemistry and fuel-nitrogen conversion in a laminar premixed flame of morpholine as a model biofuel. Combust. Flame 2011, 158, 1647-1666. 


\section{TOC}

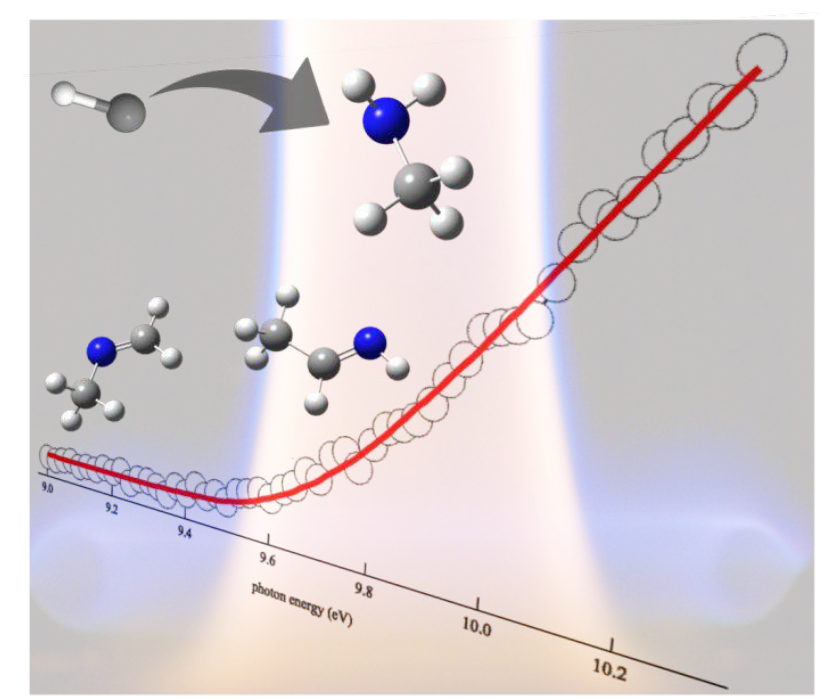

